\title{
Plankton, Aerosol, Cloud, ocean Ecosystem (PACE) Mission Integration and Testing
}

\author{
Susanna Petro \\ NASA/Goddard Space Flight Center \\ 8800 Greenbelt Road \\ Greenbelt, MD 20771 \\ 301-286-2039 \\ susanna.petro-1@nasa.gov
}

George Hilton

Newton Engineering and Product Development

Work performed for NASA/Goddard Space Flight Center

8800 Greenbelt Road

Greenbelt, MD 20771

301-286-3759

george.m.hilton@nasa.gov

\author{
Karen Pham \\ NASA/Goddard Space Flight Center \\ 8800 Greenbelt Road \\ Greenbelt, MD 20771 \\ 301-286-7525 \\ karen.pham@nasa.gov
}

\begin{abstract}
This paper describes the plans, flows, key facilities, components and equipment necessary to fully integrate, functionally test and qualify the Plankton, Aerosol, Cloud, ocean Ecosystem (PACE) Observatory. PACE is currently in the design phase of mission implementation. It is scheduled to launch in 2022, extending and improving NASA's twenty-year record of satellite observations of global ocean biology, aerosols and clouds. PACE will advance the assessment of ocean health by measuring the distribution of phytoplankton, which are small plants and algae that sustain the marine food web. It will also continue systematic records of key atmospheric variables associated with air quality and the Earth's climate. The PACE observatory is comprised of the spacecraft and three instruments, an Ocean Color Instrument (OCI) and two polarimeters, the HyperAngular Rainbow Polarimeter 2 (HARP2) and the SpectroPolarimeter for Exploration (SPEXone). The spacecraft and the OCI, which is the primary instrument, are developed and integrated at the NASA Goddard Space Flight Center (GSFC). The OCI is a hyper-spectral scanning (HSS) radiometer designed to measure spectral radiances from the ultraviolet to shortwave infrared (SWIR) to enable advanced ocean color and heritage cloud and aerosol particle science. The HARP2 and SPEXone are secondary instruments on the PACE observatory, acquired outside of GSFC. The Hyper-Angular Rainbow Polarimeter instrument (HARP2) is a wide swath imaging polarimeter that is capable of characterizing atmospheric aerosols for purposes of sensor atmospheric correction as well as atmospheric science. The SPEXone provides atmospheric aerosol and cloud data at high temporal and spatial resolution. This paper will focus on the Integration and Test (I\&T) activities for the PACE mission at NASA GSFC. This I\&T phase consists of mechanical, electrical and thermal integration and test of all the spacecraft subsystems and the integration of the instruments with the spacecraft. The PACE observatory environmental tests include electromagnetic interference (EMI)/electromagnetic compatibility (EMC), vibration, acoustics, shock, thermal balance, thermal vacuum, mass properties and center of gravity. This paper will also discuss the observatory shipment to the launch site as well as the launch site processing.
\end{abstract}

\section{Table of Contents}

1. INTRODUCTION ............................................... 2

1.1 PACE MISSION OVERVIEW ...................................... 2

1.2 OCI OVERVIEW................................................... 4

1.3 SPEXONE POLARIMETER............................................ 6

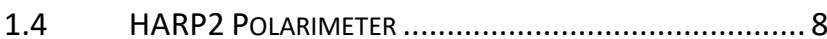

2. INTEGRATION AND TEST GROUND SUPPORT EQUIPMENT (GSE) .................................................8

3. PACE I\&T GROUND DATA SYSTEM $\ldots \ldots \ldots \ldots \ldots \ldots \ldots \ldots . \ldots$

3.1 INTEGRATED TEST AND OPERATIONS SYSTEM (ITOS) ...... 9

3.2 FRONT END DATA SYSTEM (FEDS) ............................ 9

XINA (NOT AN ACRONYM) …................................ 9

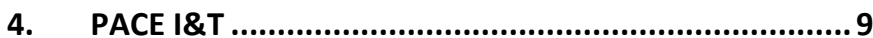

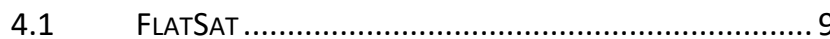

4.2 SPACECRAFT INTEGRATION AND TEST ........................ 10

4.3 OBSERVATORY INTEGRATION AND TEST .................... 11

5. OCI LIMITED PERFORMANCE TEST (LPT).................. 12

5.1 THE LPT SYSTEM .............................................. 13

5.2 TRENDING VERIFICATION PLAN .............................. 14

6. PACE ALIGNMENT ....................................... 14

7. INTEGRATION AND TEST AREAS ................. 15

8. PACE OBSERVATORY ENVIRONMENTAL TESTS AND FACILITIES ...................................... 15

8.1 EMC/EMI ................................................. 15

8.2 MASS PRoperties AND CG MEASUREMENT ................. 16

8.3 VIBRATION TEST .............................................. 16

8.4 ACOUSTIC TEST ............................................... 16 
8.5 Thermal Balance/Thermal VACUum Test

9. OBSERVATORY SHIPPING .18

10. LAUNCH SITE ACTIVITIES. .18

11. CONCLUSIONS 19

APPENDIX 19

ACRONYMS AND ABBREVIATIONS 19

REFERENCES 19

BIOGRAPHY 20

\section{INTRODUCTION}

\subsection{PACE Mission Overview}

The Plankton, Aerosol, Cloud, ocean Ecosystem (PACE) mission is a strategic climate continuity mission that was defined in the 2010 document Responding to the Challenge of Climate and Environmental Change: NASA's Plan for Climate-Centric Architecture for Earth Observations and Applications from Space (referred to as the "Climate Initiative") [1]. The Climate Initiative complements NASA's implementation of the National Research Council's Decadal Survey of Earth Science at NASA, NOAA, and USGS, entitled Earth Science and Applications from Space: National Imperatives for the Next Decade and Beyond [2].

PACE will extend the high quality ocean ecological, ocean biogeochemical, cloud, and aerosol particle data records begun by NASA in the 1990 s, building on the heritage of the SeaViewing Wide Field-of-View Sensor (SeaWiFS), the Moderate Resolution Imaging Spectroradiometer (MODIS), the Multiangle Imaging SpectroRadiometer (MISR), and the Visible Infrared Imaging Radiometer Suite (VIIRS). The mission will be capable of collecting radiometric and polarimetric measurements of the ocean and atmosphere, from which these biological, biogeochemical, and physical properties will be determined. PACE data products will not only add to existing critical climate and Earth system records, but also answer new and emerging advanced science questions related to Earth's changing climate.

PACE is classified as a Category 2 mission, per the criteria in NASA Procedural Requirement (NPR) 7120.5E, NASA Space Flight Program and Project Management Requirements. The mission classification is C according to NPR $8705.4 \mathrm{~B}$, Risk Classification for NASA Payloads.

The PACE observatory is comprised of three instruments, an Ocean Color Instrument (OCI) and two polarimeters, the Hyper-Angular Rainbow Polarimeter 2 (HARP2) and the Spectro-Polarimeter for Exploration (SPEXone). The OCI is the primary instrument on the observatory and is being developed at Goddard Space Flight Center (GSFC). The OCI is a hyper-spectral scanning (HSS) radiometer designed to measure spectral radiances from the ultraviolet to shortwave infrared (SWIR) to enable advanced ocean color and heritage cloud and aerosol particle science. The HARP2 and SPEXone are secondary instruments on the PACE observatory. They will be contributed by a consortium based in the Netherlands and University of Maryland Baltimore County, respectively. The HARP2 is a wide swath imaging polarimeter that is capable of characterizing atmospheric aerosols for purposes of sensor atmospheric correction as well as atmospheric science. The SPEXone provides atmospheric aerosol and cloud data at high temporal and spatial resolution.

This three-instrument PACE mission has the following multiple scientific goals:

- Extending key systematic ocean biological, ecological, and biogeochemical climate data records and cloud and aerosol climate data records;

- Making global measurements of ocean color data products that are essential for understanding the global carbon cycle and ocean ecosystem responses to a changing climate;

- Collecting global observations of aerosol and cloud properties, focusing on reducing the largest uncertainties in climate and radiative forcing models of the Earth system; and,

- Improving our understanding of how aerosols influence ocean ecosystems and biogeochemical cycles and how ocean biological and photochemical processes affect the atmosphere.

The PACE satellite is planned for a launch in late 2021or early 2022. The PACE project office at the NASA GSFC is responsible for the satellite development, launch and operations. The mission is planned for launch into a sun synchronous polar orbit at $676.5 \mathrm{~km}$ with an inclination of $98^{\circ}$ and a 1 PM local ascending node crossing time. The spacecraft bus will host the OCI, HARP2 and SPEXone instruments. The GSFC PACE Project office will oversee the mission and the development of the satellite, launch vehicle, mission operations control center, and operations. The Headquarters Program Science will separately fund the science data processing system and competed science teams, which will include field-based vicarious calibration and data product validation efforts to support the Project science team.

NASA Headquarters has directed the mission development to be guided by a Design-to-Cost (DTC) process. All elements of the mission, other than the cost, are in the DTC trade space. At the heart of the DTC process are the mission studies, performed across all the mission elements. The mission studies will be used to define appropriate approaches within and across elements while maximizing science capabilities at a high cost confidence. Mission baseline requirements development is also embedded within the DTC process, as these requirements were not established at the onset of the mission concept development. Baseline mission requirements will be a product of the mission studies and will be defined by the project office as part of the DTC process.

The PACE mission consists of four major segments: space segment (SS), ground segment (GS), science data segment (SDS), and the launch segment (LS). 
- The space segment consists of the spacecraft bus, the OCI, HARP2 and SPEXone instruments. The spacecraft and OCI are being developed and integrated at GSFC. HARP2 and SPEXone instruments are being procured outside of GSFC. The spacecraft and instruments will be integrated as the PACE observatory at GSFC.

- The GS and associated Mission Operations Center (MOC) will be developed, integrated, and operated at GSFC. The GS provides for the command and control and health and safety monitoring of the PACE observatory on-orbit, as well as ensuring the science data are accounted for and delivered to the SDS. The MOC will contain the flight operations team (FOT) and will be managed by the PACE project through observatory commissioning. After commissioning, the FOT will be managed by the GSFC Earth Science Mission Operations (ESMO) office. The MOC performs all real time operations and off-line operations functions, including planning and scheduling, orbit and attitude analysis, housekeeping telemetry data processing, monitoring/managing the spacecraft and instruments, first line health/safety for the instruments, and housekeeping archiving and analysis.

- The SDS will be located at GSFC, but managed (separately from the project) by the NASA Headquarters Earth Sciences Division (ESD). The SDS will ingest, apply calibration and science algorithms, and process the science data, provide science software development and algorithm integration, act as the science data interface to the science team, and deliver all of the science data products to the NASA-assigned Distributed Active Archive Center (DAAC).

- The LS includes a launch vehicle to be selected and procured by the NASA Launch Services Program at the Kennedy Space Center (KSC).

The project will utilize the NASA/GSFC institutional capabilities such as the Flight Dynamics Facility (FDF), Near Earth Network (NEN), Ocean Biology Processing Group (OBPG), Space Network (SN), and NASA Integrated Services Network (NISN). PACE plans to generate 3.5 Terabits of science data daily. The data are downlinked from the observatory during 12 to14 daily contacts via Ka-band communications to the NEN's ground stations. The observatory will also receive ground commands and transmit real-time housekeeping telemetry via an S-band two-way link through the NEN during nominal operations. The observatory also has the capability of receiving ground commands and transmitting real-time housekeeping telemetry, via S-Band, through the SN during critical or contingency operations. Table 1 shows the PACE mission overview. Figure 1 shows the PACE observatory mechanical view and figure 2 shows the PACE observatory in the stowed/launch configuration.

\begin{tabular}{|c|c|}
\hline Parameter & Value \\
\hline Mission & Directed, Design To Cost \\
\hline Mission Life & $\begin{array}{l}3 \text { years, Class } C \text {, with orbit maintenance } \\
\text { capabilities for } 10 \text { years }\end{array}$ \\
\hline Launch Vehicle & Atlas V , Antares 231, Falcon 9 \\
\hline Launch & $2021-2022$ \\
\hline Resolution & $\begin{array}{l}\text { Earth surface spatial resolution at nadir } \\
\text { of } 1 \text { kilometer }{ }^{2} \text { or better for all science } \\
\text { bands }\end{array}$ \\
\hline Orbit & $676.5 \mathrm{~km}$, Sun Sync, inclination of $98^{\circ}$ \\
\hline Instrument Suite & OCI, SPEXone, HARP \\
\hline Observatory Dimensions & $1.5 \mathrm{~m} \times 1.5 \mathrm{~m} \times 3.2 \mathrm{~m}$ \\
\hline Observatory Mass & $1700 \mathrm{~kg}$ NTE \\
\hline Observatory Power & 1000 W NTE \\
\hline Coverage $-\mathrm{OCI}$ & $\begin{array}{l}2 \text { day global coverage at } 60^{\circ} \text { instrument } \\
\text { view angle. }\end{array}$ \\
\hline Sun Glint Mitigation $\mathrm{OCI}$ & $\begin{array}{l}\text { OCI Boresight Tilted } \\
+/-20^{\circ} \text { off Nadir, Along Track }\end{array}$ \\
\hline $\begin{array}{l}\text { Pointing Knowledge } \\
\text { Pointing Control }\end{array}$ & $\begin{array}{l}90 \text { arcseconds } 3 \text {-sigma } \\
613 \text { arcseconds 3-sigma }\end{array}$ \\
\hline RF Communication & $\begin{array}{l}\text { S-Band - Command \& Telemetry } \\
\text { Ka-Band - Science Data }\end{array}$ \\
\hline Data Storage & $\begin{array}{l}7 \text { Orbits, totaling about } 1.7 \text { terabytes } \\
\left(1.7 \times 10^{12} \text { bytes }\right) \text { of data. }\end{array}$ \\
\hline $\begin{array}{l}\text { On-Orbit Absolute Gain, } \\
\text { K1, Calibration }\end{array}$ & $\begin{array}{l}\text { Vicarious Calibration - UVNIR } \\
\text { Solar Calibration - SWIR }\end{array}$ \\
\hline $\begin{array}{l}\text { On-Orbit Gain, K2, } \\
\text { Degradation Trending }\end{array}$ & $\begin{array}{l}\text { Bi-Monthly Lunar Calibration } \\
\text { Daily and Monthly Solar Calibration }\end{array}$ \\
\hline
\end{tabular}

Table 1. PACE Mission Overview 


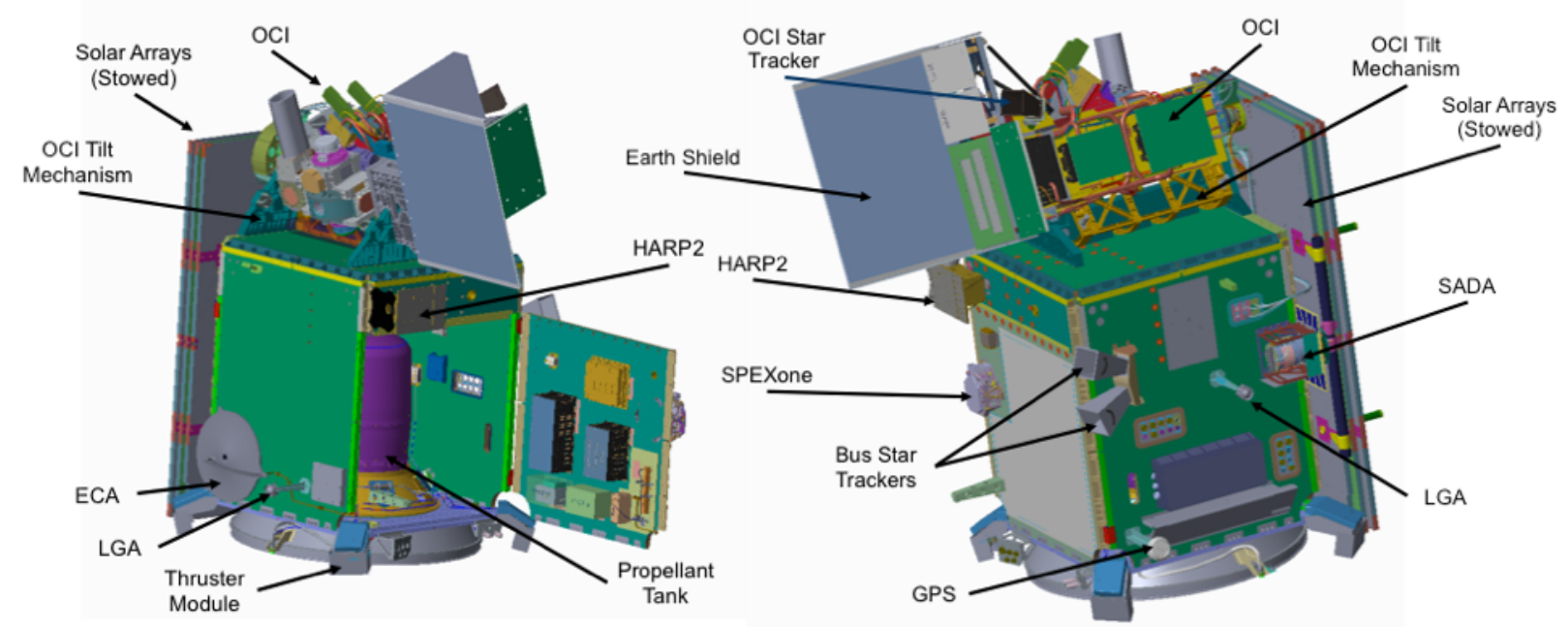

Figure 1. PACE observatory mechanical view [3]. The Solar Array Drive Assemblies (SADA) the Earth Coverage Antenna (ECA) and the Low Gain Antenna (LGA) are also shown
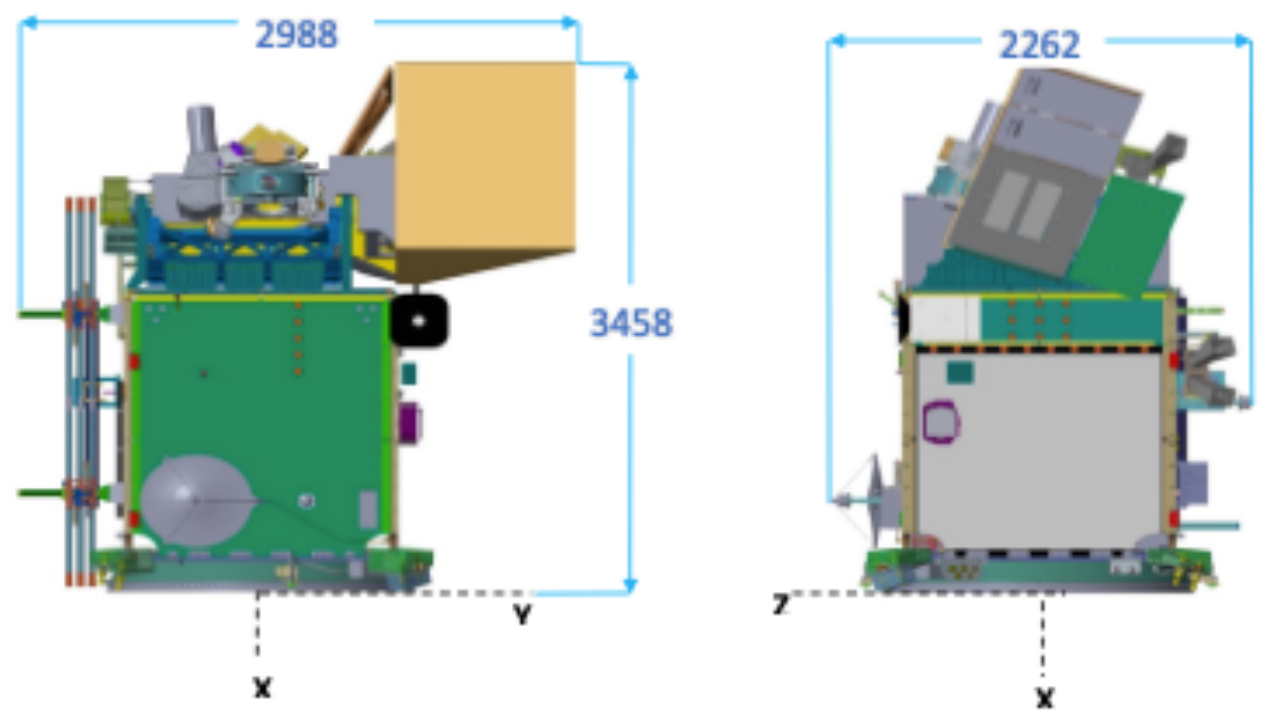

Figure 2. PACE observatory in the stowed/launch configuration [4]. Dimensions are in $\mathbf{m m}$.

\subsection{OCI Overview}

PACE's primary sensor, OCI, is a highly advanced optical spectrometer that will be used to measure properties of light over portions of the electromagnetic spectrum. It will enable continuous measurement of light at finer wavelength resolution than previous NASA satellite sensors, extending key system ocean color data records for climate studies.

The color of the ocean is determined by the interaction of sunlight with substances or particles present in seawater such as chlorophyll, a green pigment found in most phytoplankton species. By monitoring global phytoplankton distribution and abundance with unprecedented detail, the OCI will help us to better understand the complex systems that drive ocean ecology.
The OCI is being built at Goddard Space Flight Center. It will consist of a cross-track rotating telescope, thermal radiators, along with half-angle mirror and solar calibration mechanisms. The OCI's tilt will help avoid sun glint and single science detector design will inhibit image striping. Its signal-to-noise ratios will rival or exceed previous ocean color instruments. OCI elements are shown in Figure 3.

The OCI will feature:

- Cross track, $360^{\circ}$ continuous rotating telescope

- Two slit grating hyperspectral spectrographs (ultraviolet to visible \& visible to near-infrared, NIR)

- Fiber-coupled multiband filter spectrograph (NIR-to shortwave-infrared) 

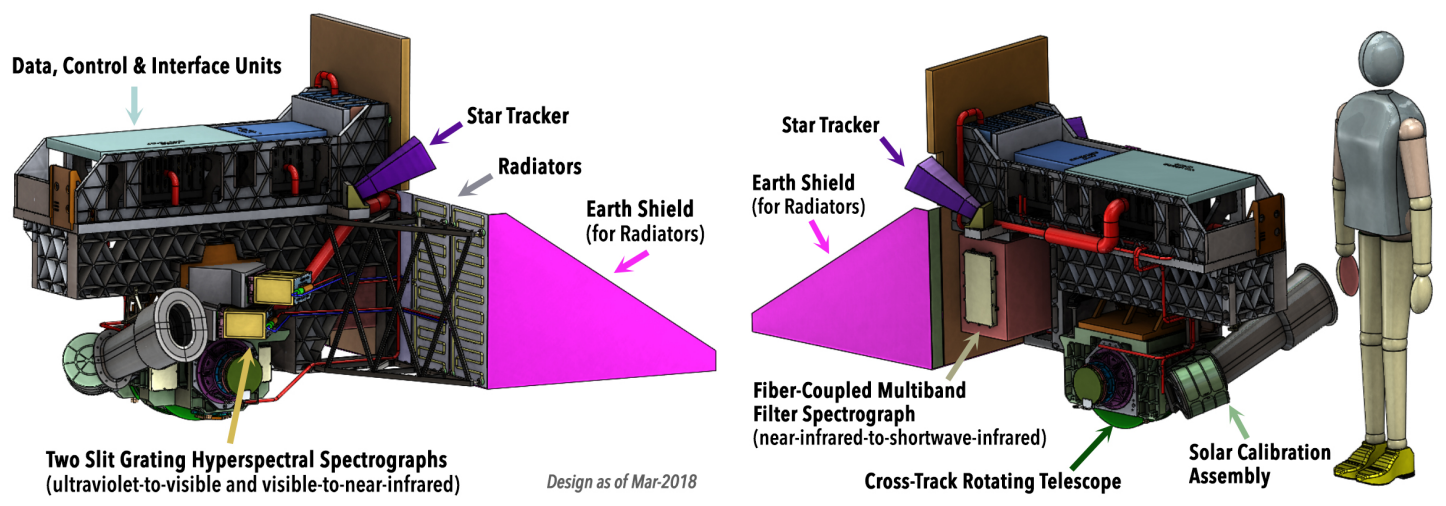

Figure 3. OCI elements

The OCI design is based on a long heritage of NASA technology development and flight programs. Its functionality - rotating telescope (mechanism and timing), charged couple device (CCD) detector, optics - benefits from previous technology development efforts such as Ocean Radiometer for Carbon Assessment (ORCA).

The OCI's operational concept, cross-track rotating telescope/half-angle mirror, system timing, and data processing infrastructure have been successfully used on previous and existing flight missions such as the Coastal Zone Color Scanner or CZCS (1978 to 1986), Sea-Viewing Wide Field-of-View Sensor or SeaWiFS (1997 to 2010), Suomi National Polar-orbiting Partnership (Visible Infrared Imaging Radiometer Suite or VIIRS), and Aqua and Terra (Moderate Resolution Imaging Spectroradiometer or MODIS instrument). In addition, the OCI's avionics (for communications and positioning) will use a significantly smaller electronics system developed by the iMUSTANG effort.

OCI is a hyperspectral imaging radiometer whose continuous coverage extends from 340 to $890 \mathrm{~nm}$ in the ultraviolet (UV) to near infrared spectrum at $5 \mathrm{~nm}$ resolution (with bandwidth at $5 \mathrm{~nm}$ ). The goal is to increase the spectral steps to $2.5 \mathrm{~nm}$ (with bandwidth remaining at $5 \mathrm{~nm}$ ), which will be confirmed at the PACE Critical Design Review in Winter 2019/2020. It also includes seven discrete bands from $940 \mathrm{~nm}$ to $2260 \mathrm{~nm}$ in the shortwave infrared (SWIR) spectrum. Like SeaWiFS, OCI will perform a tilt maneuver every orbit at approximately the sub-solar point to avoid sun glint reflected off the ocean, looking $20^{\circ}$ north (fore) in the northern hemisphere and $20^{\circ}$ south (aft) in the southern hemisphere.
The OCI telescope will scan from east to west at a rotation rate of $5.77 \mathrm{~Hz}$, acquiring Earth view data at a $1 \mathrm{~km} \mathrm{x} 1 \mathrm{~km}$ ground sample footprint at nadir and an angular range of $\pm 56.5^{\circ}$ for a ground swath width of $2663 \mathrm{~km}$. The OCI fore optics design follows that of SeaWiFS, with a rotating telescope, a half angle mirror, and a depolarizer that is transmissive (rather than reflective as with CZCS and SeaWiFS). Dichroics - material which splits visible light into distinct beams - direct the light to three different focal planes: 1) a blue spectrograph (340-605 $\mathrm{nm}$ ) with wavelength separation via grating and light detection using a CCD; 2) a red spectrograph (600-890 nm) using the same approach; and 3) SWIR detection assembly with wavelength separation using dichroics/bandpass filters and light detection via semiconductor devices that convert light into an electrical current, known as "photodiodes."

The OCI builds on the ORCA prototype. Its SWIR detection assembly uses a new approach that guides light to individual detection units via fiber optic cables. These specialized photodiodes will employ alloys of indium gallium arsenide (InGaAs) and mercury cadmium telluride ( $\mathrm{HgCdTe})$. A subset of SWIR bands and the red spectrograph will be evaluated as part of engineering test unit development in preparation for the OCI's Critical Design Review. Subsequently, the flight unit that includes all spectral channels will be built at GSFC. Table 2 shows the OCI overview.

A detailed description of the OCI Integration and Test (I\&T) can be found in reference [5]. 


\begin{tabular}{|c|c|}
\hline Instrument Mass & 270 kg CBE \\
\hline Instrument Power & 315 W CBE , Orbital Average \\
\hline Thermal System & Passive Cooling with Loop Heat Pipes \\
\hline Mechanisms & $\begin{array}{l}\text { Rotating Telescope Mechanism }(\sim 6 \mathrm{~Hz}) \\
\text { Half Angle Mirror Mechanism }(\sim 3 \mathrm{~Hz}) \\
\text { Solar Calibration Mechanism ( }<4 \mathrm{k} \text { Cycle) }\end{array}$ \\
\hline Deployments & Rotating Telescope Launch Locks \\
\hline Ground Sample Distance & $1050 \mathrm{~m}$ \\
\hline Aperture & $90 \mathrm{~mm}$ \\
\hline iFOV & $0.08^{\circ}$ Along Track $x 1.42^{\circ}$ Cross Track \\
\hline Effective Focal Length & $0.134 \mathrm{~m}$ \\
\hline System F/Number & 1.49 \\
\hline Total Field of Regard & $+/-56.5^{\circ}$ \\
\hline Dynamic Range & $S N R$ at $L_{t x p}$, No Saturation at $L_{\text {max }}$ \\
\hline UVNIR Bands (nm) & $342.5 \mathrm{~nm}-887.5 \mathrm{~nm}, 5 \mathrm{~nm}$ Resolution \\
\hline NIRSWIR Bands (nm) & $940,1038,1250,1378,1615,2130,2260$ \\
\hline UVVIS \& VISNIR FPAS & $\begin{array}{l}2 \text { CCDs, } 128 \times 512,26 \text { micron pixel } \\
\text { Integrated } 14 \text { Bit ADC }\end{array}$ \\
\hline NIRSWIR FPAs & $\begin{array}{l}32 \mathrm{MCT} \text { Photodiodes, }<250 \text { micron } \\
\text { Analog output to remote SIDECAR ASIC }\end{array}$ \\
\hline $\begin{array}{l}\text { Relative Radiometric } \\
\text { Accuracy }\end{array}$ & $<0.5 \%$ Pre-Launch 1-sigma \\
\hline SNR @ L LtxR. & $\begin{array}{ll}>1000: 1 & 340-700 \mathrm{~nm} \\
>600: 1 & 700-865 \mathrm{~nm} \\
>50: 1 & 940-2260 \mathrm{~nm}\end{array}$ \\
\hline $\begin{array}{l}\text { On-Board Solar Calibration } \\
\text { Assembly }\end{array}$ & $\begin{array}{l}\text { Daily and Monthly Solar Calibration } \\
\text { Targets }\end{array}$ \\
\hline Orbital Average Data Rate & $13 \mathrm{Mbps}$ up to $40 \mathrm{Mbps}$ \\
\hline
\end{tabular}

Table 2. OCI overview

\subsection{SPEXone Polarimeter}

PACE's SPEXone instrument is a multi-angle polarimeter. It measures the intensity, Degree of Linear Polarization (DoLP) and Angle of Linear Polarization (AoLP) of sunlight reflected back from Earth's atmosphere, land surface, and ocean. The focus of the SPEXone development is to achieve a very high accuracy of DoLP measurements, which facilitates accurate characterization of aerosols in the atmosphere.

Aerosols are small solid or liquid particles suspended in the air that affect climate directly through interaction with solar radiation. Aerosols affect climate indirectly by changing the micro- and macro-physical properties of clouds. According to the Intergovernmental Panel on Climate Change, aerosols are the largest source of error in quantifying the radiative forcing of climate change. SPEXone will enable measurements of optical and micro-physical properties of aerosols with unprecedented detail and accuracy.

SPEXone is being developed by a Dutch consortium consisting of SRON Netherlands Institute for Space Research and Airbus Defence and Space Netherlands, supported by optical expertise from TNO. SRON and Airbus DS NL are responsible for the design, manufacturing and testing of the instrument. The scientific lead is in the hands of SRON. SPEXone is a publicprivate initiative funded by the Netherlands Space Office (NSO), the Netherlands Organization of Scientific Research (NWO), SRON, and Airbus DS NL.

SPEXone will feature:

- A compact three-mirror segmented telescope assembly (patented by the consortium) to gather light from $0^{\circ}, \pm 20^{\circ}$ and $\pm 50^{\circ}$ (at satellite level) and direct the light towards a common entrance slit of a spectrometer

- Polarization Modulation Optics (PMO) to encode the state of linear polarization in the intensity spectrum as a sinusoidal modulation

- A compact and lightweight all-reflective imaging grating spectrometer.

For the polarization modulation technique, SPEXone is based on heritage in ground-based and airborne applications.

The spectral modulation technology was invented by the group of Prof. Keller (Leiden University) and has been further developed in the Netherlands through several national programs. 
Major steps in this project have been the development, characterization, and ground-based field-testing of a SPEX prototype (originally designed for a Mars orbiter) and the upgrade of the SPEX prototype into a stand-alone instrument, SPEX airborne, for operating on the high-altitude $(21 \mathrm{~km}$ or 13 mi) NASA ER-2 research aircraft.

The spectrometer of SPEXone is based on Dutch heritage with the Sentinel-5 precursor Tropomi instrument, its predecessor OMI, and the derived compact version Spectrolite.

SPEXone is a spectro-polarimeter that provides continuous wavelengths coverage in the range $385-770 \mathrm{~nm}$. Spectral resolution is $2-5 \mathrm{~nm}$ for radiance and $10-40 \mathrm{~nm}$ for DoLP. It observes a ground pixel under 5 viewing angles $\left(0^{\circ}, \pm 20^{\circ}\right.$ and $\pm 58^{\circ}$ on ground), where the $\pm 20^{\circ}$ viewports will be used for cross calibration with OCI.

A compact three-mirror segmented telescope assembly [6] (patented by the consortium) gathers light from $0^{\circ}, \pm 20^{\circ}$ and $\pm 50^{\circ}$ (at satellite level) and directs the light towards a common entrance slit of a spectrometer. There are several optical components before and after the slit that together form the polarization modulation optics (PMO). The PMO encode the state of linear polarization in the intensity spectrum as a sinusoidal modulation. The polarizing beam splitter in the PMO provides two complementary light beams where $\mathrm{I}$ is the intensity of the incoming light on the instrument, P the DoLP, $\beta$ the Angle of Linear Polarization (AoLP), $\lambda$ is wavelength, and $\delta$ is the instrumental retardance.

$$
I_{+/-}(\lambda)=\frac{1}{2} I(\lambda)\left\{1 \pm P(\lambda) \cos \left(\frac{2 \pi \delta(\lambda)}{\lambda}+2 \beta(\lambda)\right)\right\}
$$

By combining I+ and I-, I can be determined at spectrometer resolution and the DoLP and AoLP at a resolution determined by the modulation width. I+ and I- both enter the spectrometer and are focused onto the detector as two pairs of five spectral images. SPEXone has optimized telescopes for each viewing angle, such that for all viewing angles a $100 \mathrm{~km}$ swath (ACT direction) is imaged onto the detector with a spatial resolution close to $5.4 \mathrm{~km}$ (3.4 mi) at a Spatial Sampling Distance (SSD) of $2.7 \mathrm{~km}(1.7 \mathrm{mi})$. In the ALT direction, Nyquist sampling is achieved by performing two image acquisitions per $4.6 \mathrm{~km}(2.9$ mi) sub-satellite point movement. Figure 4 shows the SPEXone instrument. Table 3 shows the SPEXone overview.

\begin{tabular}{|l|l|}
\hline Instrument Mass & Less than $15 \mathrm{~kg}$ \\
\hline Instrument Power & Less than $20 \mathrm{~W}$ \\
\hline Spatial Sampling & $2.7 \times 2.3 \mathrm{~km} 2$ \\
\hline Spatial Resolution & $5.4 \times 4.6 \mathrm{~km} 2$ \\
\hline Swath \& Coverage & $\begin{array}{l}100 \mathrm{~km}(62 \mathrm{mi}) \\
\text { month. }\end{array}$ \\
\hline Spectral Range & $\mathbf{3 8 5 - 7 7 0} \mathrm{nm}$ \\
\hline Spectral Resolution & $\mathbf{2 - 5} \mathrm{nm}$ for radiance, $10-40 \mathrm{~nm}$ for DoLP \\
\hline Viewing Angles & $0^{\circ}, \pm 20^{\circ}$ and $\pm 58^{\circ}$ (on ground) \\
\hline Accuracy & $\mathbf{0 . 0 0 3}$ polarimetric, $2 \%$ radiometric. \\
\hline
\end{tabular}

Table 3. SPEXone overview [7]

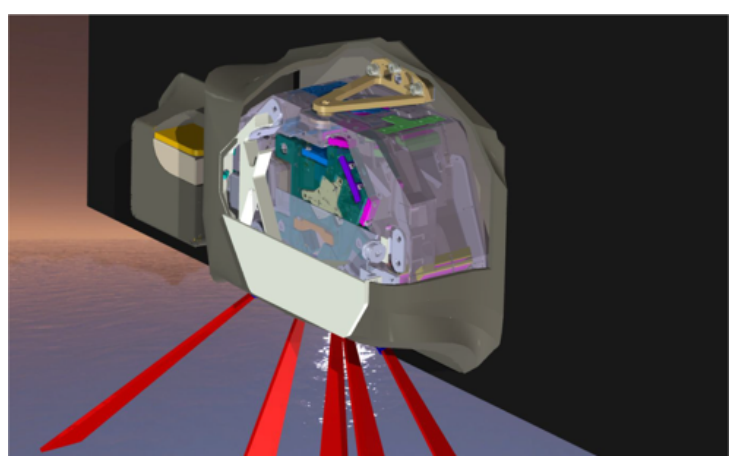

Figure 4. Artist impression of SPEXone instrument in space - (Airbus Defence and Space Netherlands \& SRON Netherlands Institute for Space Research 


\subsection{HARP2 Polarimeter}

HARP2 (Hyper-Angular Rainbow Polarimeter \#2) is a wide angle imaging polarimeter designed to measure aerosol particles and clouds, as well as properties of land and water surfaces. The amount and type of particles in suspension in the atmosphere are relevant to applications pertaining to health effects, cloud life cycle and precipitation, climate, etc. HARP2 will combine data from multiple along track viewing angles (up to 60), four spectral bands in the visible and near infrared ranges, and three angles of linear polarization to measure the microphysical properties of the atmospheric particles including their size distribution, amount, refractive indices and particle shape.

HARP2 is a contributed instrument to the PACE mission, designed and built by UMBC's Earth and Space Institute. Figure 5 shows the HARP2 instrument. Table 4 shows the HARP2 overview.

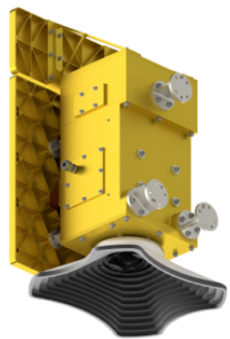

Fig 5. Artist impression of HARP2

\begin{tabular}{|c|c|}
\hline Instrument Mass & $9.6 \mathrm{~kg}$, current best estimate \\
\hline Instrument Power & $11.5 \mathrm{~W}$, current best estimate \\
\hline Volume & $316 \times 355 \times 440 \mathrm{~mm}$, current best estimate. \\
\hline Field of View & $94^{\circ}$ cross track; $+/-57^{\circ}$ along track \\
\hline Along Track Viewing Angles & $\begin{array}{l}60 \text { along track viewing angles for the } 669 \\
\text { nm band; } 10 \text { along track viewing angles for } \\
\text { the other } 3 \text { bands }(441,549 \text {, and } 873 \mathrm{~nm})\end{array}$ \\
\hline Coverage & 2 days global coverage at $2.6 \mathrm{~km}$ resolution \\
\hline Spectral Bands & $\begin{array}{l}\text { Center wavelengths: } 441,549,669,873 \mathrm{~nm} \text {; } \\
\text { Bandwidths: } 15,12,16 \text { and } 43 \mathrm{~nm}\end{array}$ \\
\hline Polarization Angles & $0^{\circ}, 45^{\circ}$ and $90^{\circ}$ \\
\hline Calibration & $\begin{array}{l}\text { Polarization accuracy }<1 \% \text {. Monthly lunar } \\
\text { and solar calibrations. Cross calibration } \\
\text { with OCI and SPEXone instruments; } \\
\text { Internal flat field calibrator to extend } \\
\text { calibrations over the whole field of view }\end{array}$ \\
\hline
\end{tabular}

Table 4. HARP2 overview

\section{INTEGRATION AND TEST GROUND SUPPORT EQUIPMENT (GSE)}

The PACE I\&T team worked with all of the subsystem Product Design Leads (PDLs) [8] and systems engineering to identify any non-flight Ground Support Equipment (GSE) required to support PACE I\&T activities. This GSE falls into two categories: standard GSE, which is typically used regardless of mission specific requirements, and mission unique GSE. The
PACE unique GSE is specific to the type of observatory testing that PACE requires. The following are the categories of PACE unique GSE:

- Electrical GSE (EGSE)

- Mechanical GSE (MGSE)

- Optical GSE (OGSE)

- Thermal GSE (TGSE)

Example of PACE unique GSE are shown in figures 6, 7, 8, 9, 13,14 and 15 .

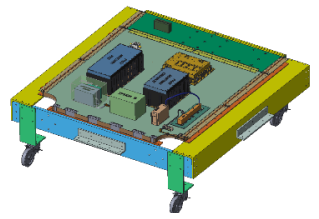

Fig 6. PACE MGSE: Equipment Panel Handling/Turnover Fixture

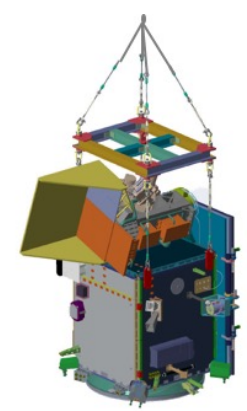

Fig 7. PACE MGSE: Lift Slings

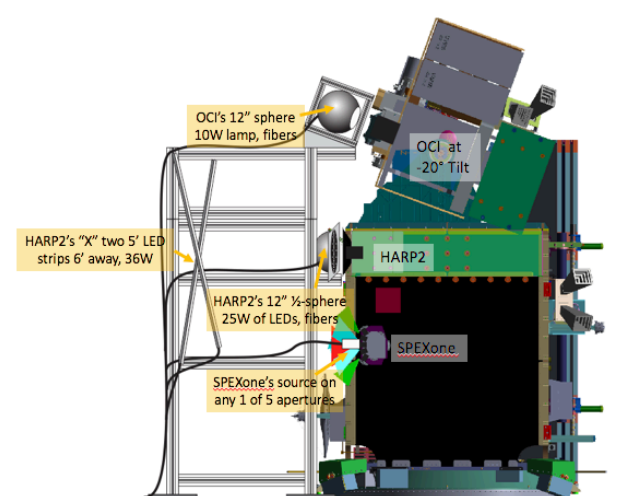

Fig 8. PACE OGSE

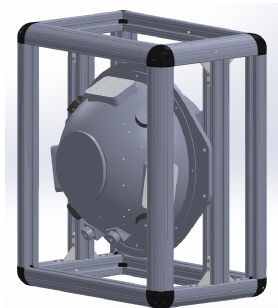

Fig 9. PACE and OCI OGSE, 12" Integrating Sphere

All PACE test equipment shall be periodically calibrated, and will have certification procedures performed prior to operation 
per the equipment manufacturer's instructions and GPR 8730.1I, Calibration and Metrology [9]. When EGSE is moved and reconfigured, for example prior to start of environmental testing, an EGSE cert procedure will be performed. All equipment requiring calibration shall have a calibration sticker that indicates that the unit is in calibration. Tracking and scheduling the calibration of this equipment will be performed by the PACE I\&T Electrical Technician.

To avoid accidental power off of power supplies, all critical power supply On/Off switches shall be covered with a springloaded cover. To avoid accidental shorting from external objects of internal power busses, all in-house manufactured or commercial equipment shall have protective covers. All EGSE that interfaces directly with flight equipment shall have a Failure Modes and Effects Analysis (FMEA) performed to ensure that no failure of the EGSE can cause a failure or an overstressed condition of flight hardware. All EGSE connectors mating to flight hardware will be flight connectors.

\section{PACE I\&T GROUND DATA SYSTEM}

During FlatSat testing, spacecraft and observatory I\&T, the I\&T Ground Data System (GDS) will provide the data capture, acquisition, decommutation, command generation, telemetry conversion to engineering data, display of engineering data, functional test procedure execution, archiving, report generation, trending, and network interface to the other EGSE. The computer system is based on the Integrated Test and Operations Systems (ITOS) and Front End Data System (FEDS) used by GSFC for other missions. The FEDS/ITOS will be connected to an uninterruptible power supply (UPS). Science data will be processed through the XINA data pipeline.

\subsection{Integrated Test and Operations System (ITOS)}

The ITOS software is Government Off-the-Shelf (GOTS) and provides real time command and control of the spacecraft and associated GSE. ITOS provides the main man-machine interface using a Commercial Off-the-Shelf (COTS) graphics display utility. ITOS provides the capability to execute Systems Test and Operations Language (STOL) driven procedures with the PACE command and telemetry Record files (REC) databases. ITOS will create STOL procedure event logs and will have access to archived telemetry for offline analysis. The ITOS primary work station is able to provide command and telemetry functions via a TCP/IP interface to the FEDS and other properly configured GSE. Each workstation will have two displays for external monitoring of telemetry/tests

\subsection{Front End Data System (FEDS)}

The FEDS is the product used for managing connections to multiple ground stations, electrical ground support equipment (EGSE), and science operations centers. FEDS strongly supports most of the Consultative Committee for Space Data Systems (CCSDS) standards for space communications that are widely accepted and used in the space industry. FEDS supports both frame and packet processing and it has archiving and playback capabilities. It can interface with multiple telemetry and command (T\&C) systems, including ITOS and ASIST.

The NASA ground stations that FEDS has full support for include:

- NASA Near Earth Network (NEN)

- Deep Space Network (DSN)

- $\quad$ TDRSS Space Network (SN)

\subsection{XINA (Not an Acronym)}

XINA is an end-to-end instrument data pipeline that has supported 5 missions, including Curiosity and MAVEN. XINA processes instrument telemetry into organized databases, allowing rapid development of powerful, and sometimes unanticipated, visualizations. The web-based user interface eliminates the need to support a distributed application and cloud-based database server allows scalability to grow with missions.

Science data formats provided:

- Real-time

- Quicklook for pass/fail to proceed during testing

- Longterm

- $\quad$ Subsystem Trending

\section{PACE I\&T}

The PACE I\&T process starts with the development of the FlatSat, a high fidelity electrical and functional representation of the spacecraft bus using engineering test units (ETUs) of the avionics components for the PACE spacecraft. Integration of the spacecraft occurs next, culminating in the performance of a Comprehensive Performance Test (CPT) dry run. Then the instruments are integrated and observatory-level testing commences. The test program will provide assurance that system-level performance requirements are met as defined in the PACE Mission Requirements Document (MRD) [10]

\subsection{FlatSat}

The purpose of the FlatSat is to verify electrical interfaces, support development and verification of the project database, dry run integration and STOL test and ops procedures and to perform fault detection and correction (FDC) and flight software (FSW) acceptance testing. All of this is performed to reduce risk prior to integration at the $\mathrm{S} / \mathrm{C}$ level. The I\&T team is the owner of the FlatSat until launch at which time the facility is turned over to the Mission Operations flight software maintenance team. FlatSat remains an active platform for use throughout the PACE mission.

The main function of the FlatSat during the integration phase is to verify component's electrical interfaces, flight and ground software, and electrical integration and STOL procedures needed to support electrical integration at $\mathrm{S} / \mathrm{C}$ level. 
Simulators provided by the GSE team will substitute the hardware that is not available for integration to the FlatSat. There is no plan to integrate flight hardware to FlatSat, although FlatSat will follow procedures that will allow for flight hardware integration (except for cleanliness requirements). FlatSat will remain configured and operational throughout the duration of the PACE Program to allow for continued software and procedure checkout during spacecraft integration, pre-launch, and post-launch (mission ops) activities. FlatSat documentation will follow the PACE Work Order Authorization (WOA) process. The GSFC Problem Record/Problem Failure Record (PR/PFR) System is used to record anomalies.

The FlatSat concept for PACE is to build a high fidelity electronics platform used to support FSW tests. The buildup process allows the integration team to verify Observatory interfaces and test procedure maturity to identify issues prior to the start of spacecraft integration. The FlatSat core consists of

\subsection{Spacecraft Integration and Test}

The objective of spacecraft integration is to integrate the harness and bus components to the structure panels and integrate the panels to the propulsion module to make up the spacecraft. The concept is to do a flat integration of the spacecraft with the structure panels on their handling fixtures. First, the main harness is integrated onto the $+Y$ panel followed by the PSE and the CAB components. After the PSE and CAB are electrically integrated, the I\&T battery and the rest of the spacecraft components, with the exception of the antennae, SADA, course sun sensors, star tracker optical bench and the GPS antenna, are mechanically and electrically integrated to their respective panels and interface tests with the PSE and $\mathrm{CAB}$ are performed. The actual order of integration of the rest of the components onto the observatory will depend on when subsystems are delivered to I\&T.

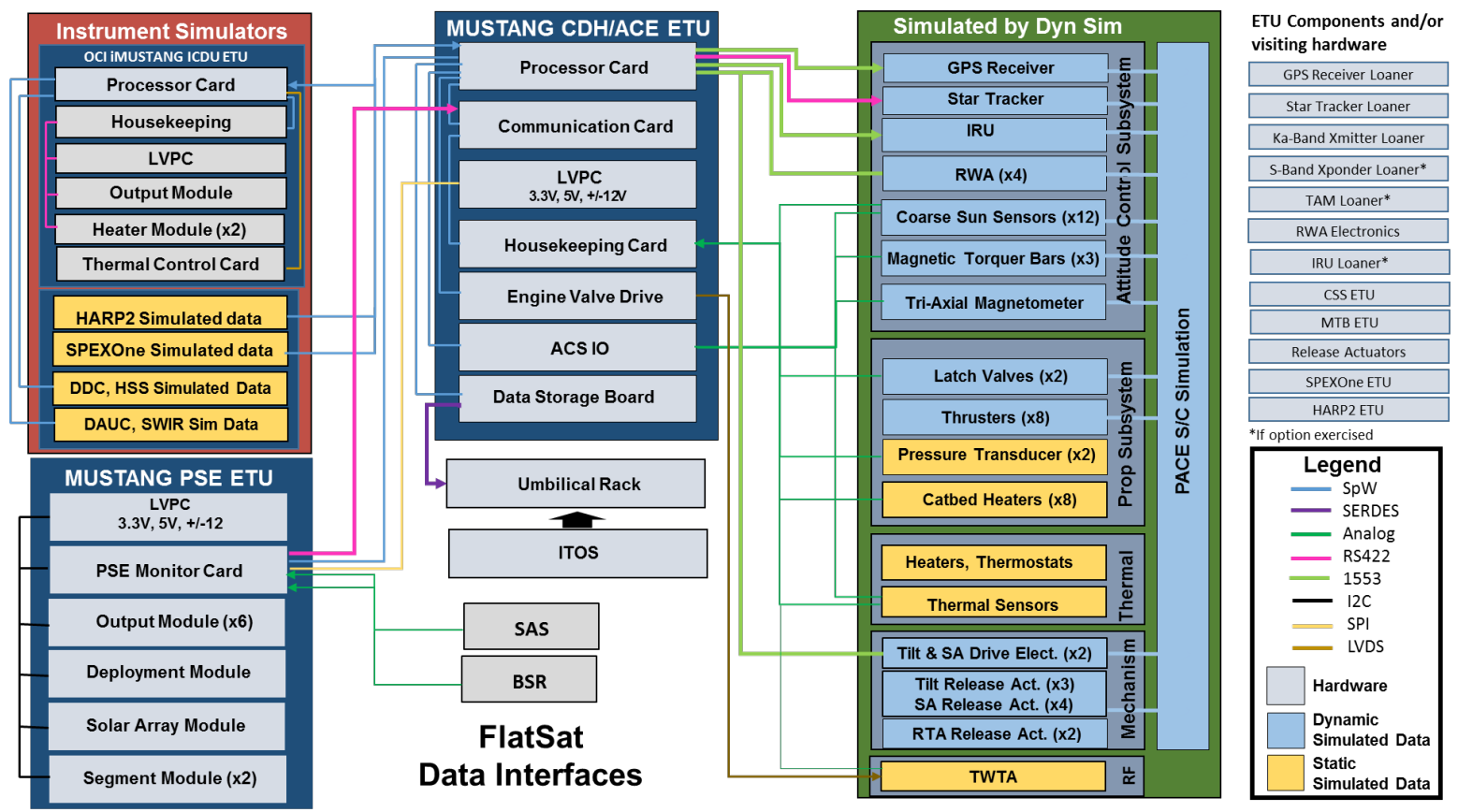

Figure 10. FlatSat Architecture (see Appendix for acronyms and abbreviations)

the avionics ETUs for the C\&DH ACE Box (CAB) component and the Power System Electronics (PSE). The Goddard Dynamic Simulator (GDS) as well as instrument simulators will also be part of the FlatSat configuration. The OCI instrument simulator will include an ETU of its Instrument Command and Data Unit (ICDU). The harness at FlatSat will also be built in a flight like configuration. The avionics along with the associated GSE make up the FlatSat core needed by both FSW and Mission Operations.

Expansion of the FlatSat by integration of other Engineering Models will not be precluded by the design or layout of the FlatSat. The addition of other Engineering Model units (or flight spares) allow for phasing out GSE that is not required to simulate the component. Figure 10 shows the FlatSat architecture.
After all the components are integrated, a dry run of the spacecraft CPT will be performed with the panels still lying flat on their respective handling fixtures. When the propulsion module is delivered to I\&T, the electrical connections between panels are disconnected and the panels integrated onto the Propulsion module. After all the panels are integrated onto the propulsion module, and before the harnesses are re-connected to the components, a safe-to-mate procedure is performed. The remaining flight hardware is integrated and the spacecraft CPT dry run $\# 2$ is performed. Figure 11 shows the top-level spacecraft I\&T flow. 


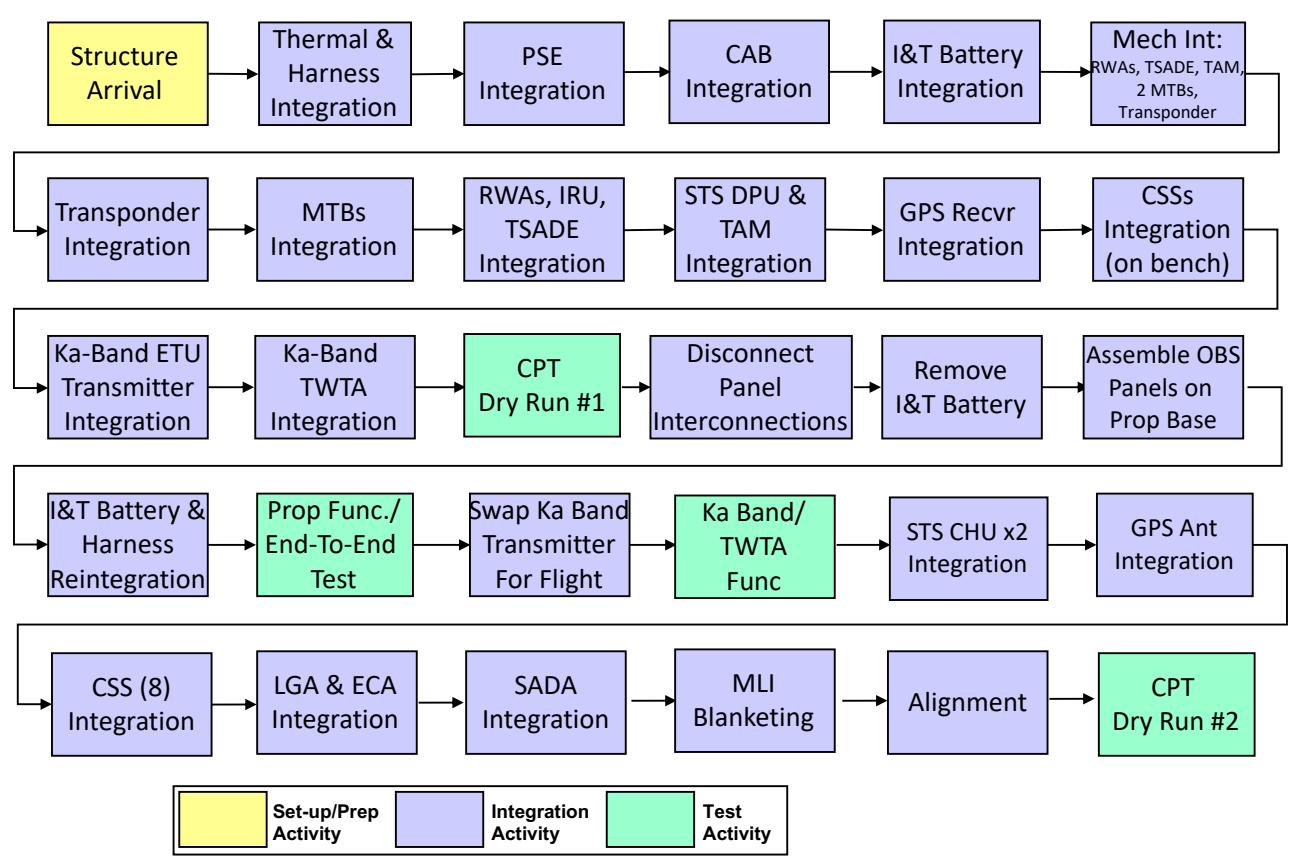

Figure 11. Top-Level Spacecraft I\&T Flow (see Appendix for acronyms and abbreviations)

\subsection{Observatory Integration and Test}

The objective of Observatory I\&T is to integrate the science instruments to the spacecraft, perform the required tests at different stages of observatory integration and subject the completed observatory to the environmental test regimen. The instruments are going to be integrated onto the Observatory in the order that they are received. However, there are no constraints that prevent them from being integrated in any order. Prior to being integrated to the Observatory, each instrument will perform an incoming instrument-level functional test. Once integrated to the observatory, the same functional or an aliveness test is run to verify the interfaces were properly integrated. It should be noted that the OCI instrument will be integrated to the tilt system prior to integration to the observatory. Once all the instruments are integrated and functionally tested on the Observatory, the preenvironment CPT is performed to serve as a baseline going into the environmental test program. After successful conduct of the CPT, the observatory EMI/EMC testing is performed and is configured to be as flight like as possible for the environmental testing including integration of the solar array for mechanical environments but not for thermal vacuum testing. Test-As-You-Fly (TAYF) exceptions are documented in the Gold Rules Compliance Document (PACE-SYS-REQ0056). The fully integrated observatory (solar array is installed after EMI/EMC) undergoes mass properties and then mechanical environmental testing which includes, 3 -axis sine vibration, acoustics and separation shock testing. Limited performance testing is performed in-between axis of vibration and after acoustics and shock testing and appendage deployments.

After mechanical environments, a deployment test is performed on the solar array, that is then de-integrated from the observatory and the observatory undergoes thermal vacuum testing. A thermal balance test is performed at the front end of the testing followed by thermal cycling. Prior to chamber pump down, a CPT is performed in ambient pressure inside the chamber with the chamber lid closed. Additional CPTs are run during TV cycling, once at the hot plateau and another at the cold plateau.

Following thermal vacuum testing a post-environment CPT is performed. The solar array is re-integrated, the flight battery installed. The observatory is now ready to be packed and shipped to the launch site. Figure 12 shows the top-level observatory I\&T flow. 


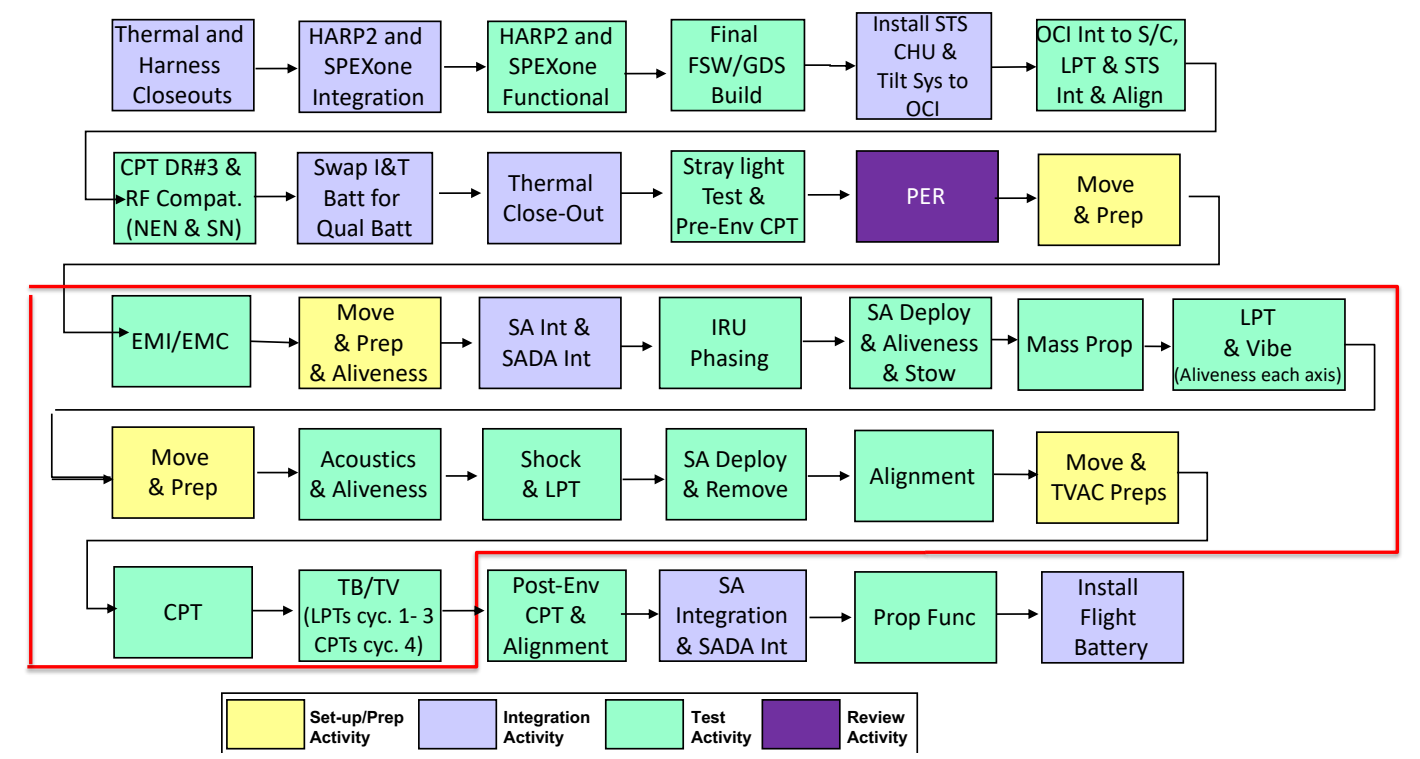

Figure 12. Top-Level Observatory I\&T Flow see MPDR presentation for box editing (see Appendix for acronyms and abbreviations)

\section{OCI LIMITED PERFORMANCE TEST (LPT)}

The OCI LPT system is designed to track and trend the spectral and radiant response of OCI at all levels of I\&T and after OCI has been integrated into the PACE spacecraft. In order to accomplish this the LPT system must reliably produce and track a stable and repeatable full spectrum radiance and several defined spectral emission lines in ambient conditions and during Thermal-Vacuum (TVAC) testing. This system must also provide well collimated narrow wavelength stable sources in both hyper-spectral channels in order to verify optical and spectral alignment. Figure 13 shows the OCI Limited Performance Test EGSE Rack.

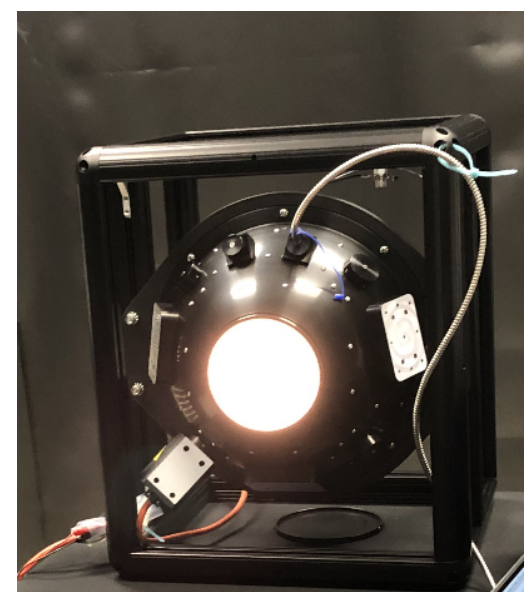

Figure 14 OCI LPT Vacuum Sphere Energized with 10W Halogen Lamp \& Lamp Radiance Benchmark

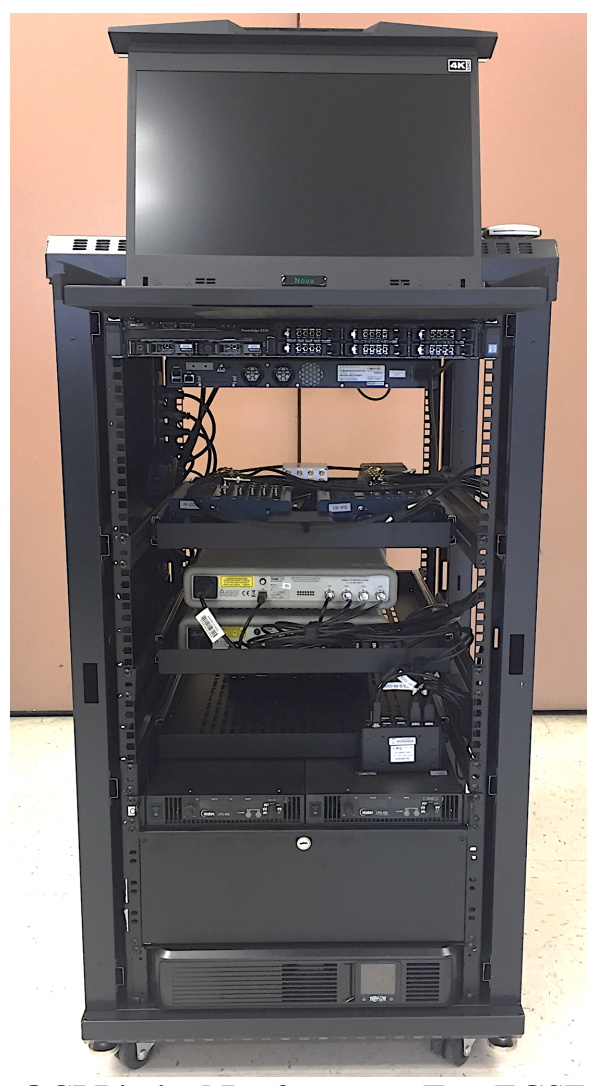

Figure 13. OCI Limited Performance Test EGSE Rack 


\subsection{The LPT system}

To produce a full spectrum radiance under these conditions a vacuum compatible 12" spectralon coated integrating sphere and $10 \mathrm{w}$ vacuum compatible halogen lamp are used (see figure 14). The lower power halogen lamps are one of the most stable and reproducible full-spectrum sources available to us, which is why it was chosen as the broad-band OCI trending source.

In addition to the halogen lamp there are 6 wavelengthspecific high-throughput fiber-optic cables attached to the 12" sphere on a vacuum feedthrough. These fiber-optic cables are connected to several accurately controlled diode sources that cover both hyper-spectral channels and two SWIR channels $(405 \mathrm{~nm}, 520 \mathrm{~nm}, 642 \mathrm{~nm}, 852 \mathrm{~nm}, 940 \mathrm{~nm}$ and $1625 \mathrm{~nm})$. Some diodes are coupled together. The feedthrough and fiber-optic cable lengths are designed for multi-vacuum chamber compatibility allowing the LPT system to be used during OCI TVAC testing and during the PACE observatory TVAC testing. Two of the 6 specialized fibers are connected to radiometers that track and document the systems radiance during ambient and vacuum testing.

There are also 2 collimated beams for each hyper-spectral channel that are produced by a dual collimator system and two fiber-coupled diode sources (520nm and $785 \mathrm{~nm}$ ), shown in figure 15 .

These collimators are designed to produce well defined spot images for both OCI hyper-spectral channels via use of refractive optics that produce a $90 \mathrm{~mm}$ well collimated beam. All diode sources in the LPT system (Vacuum sphere and collimators) are equipped with OCI instrument synchronized switching. This allows charge accumulation exposures and enables OCI to reach higher radiance levels needed for a complete operational verification. The OCI LPT Setup is shown in figure 16.

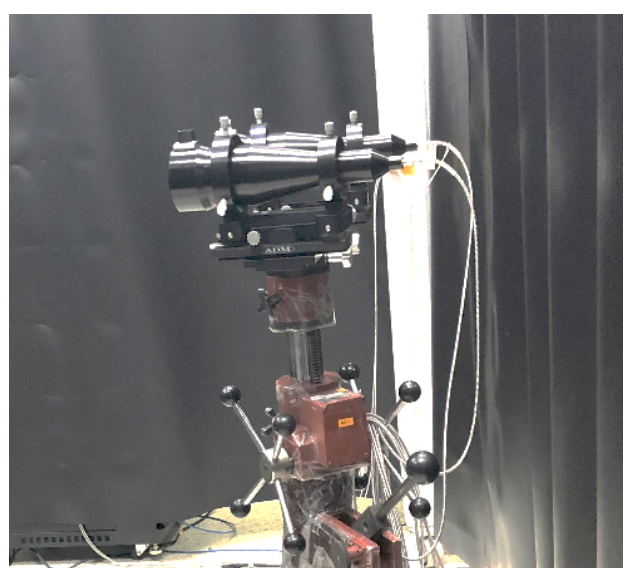

Figure 15 OCI LPT Collimator

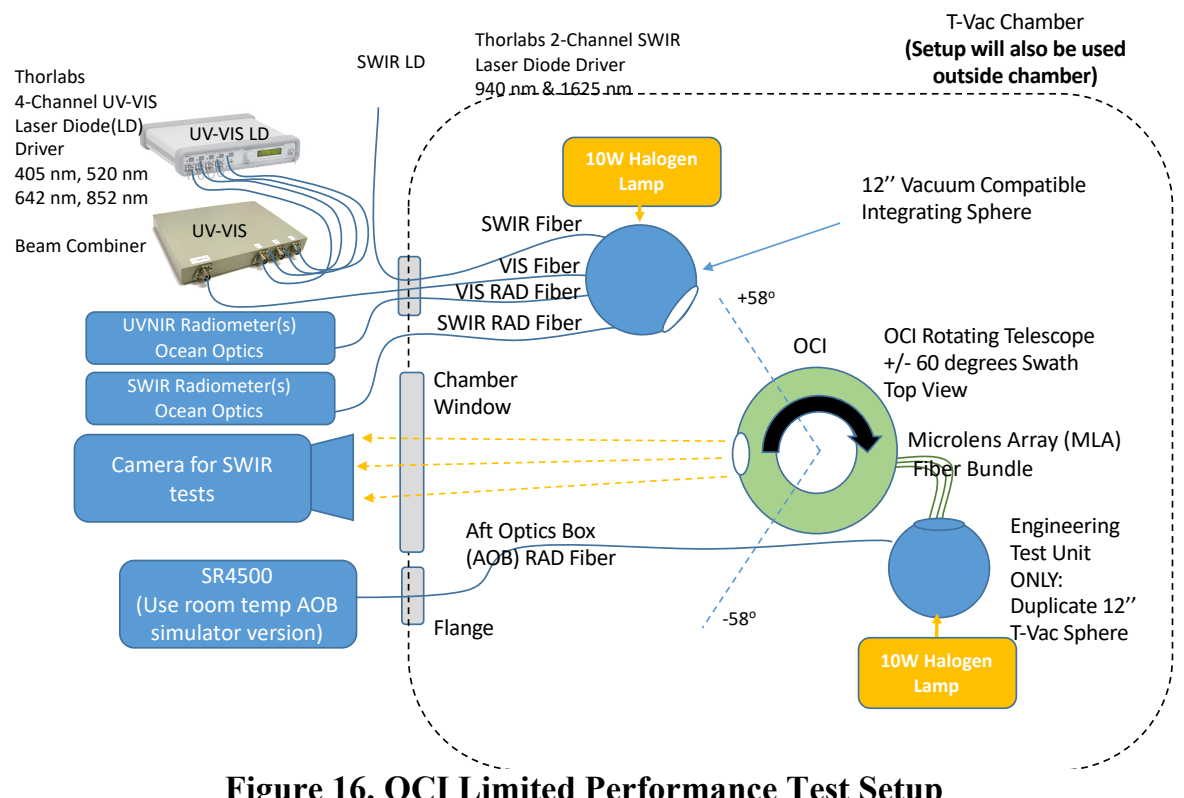

Figure 16. OCI Limited Performance Test Setup 


\subsection{Trending Verification Plan}

The LPT system will be used at each critical level of I\&T to verify the instrument is functioning properly. For Engineering Test Unit (ETU) and Flight an LPT test procedure will be performed after hyper-spectral detector integration, before and after Vibration and Acoustical testing, and before after and during TVAC testing. The LPT procedure will also be performed, multiple times, at the observatory level. These LPT procedures will ensure the proper function of the instrument and determine if and when there is a change in performance and perhaps help understand why the change occurred.

\section{PACE ALIGNMENT}

Pre- and post-alignment measurements in support of environmental testing are planned for the fully integrated Observatory requiring measurement of the pointing directions of components and instruments prior to and following specific environmental testing as defined by the PACE I\&T schedule and requirements.

The alignment flow [12] can be divided into the following major efforts:

a. Pre-Observatory I\&T Alignment - Alignment measurements required to prepare for ObservatoryLevel I\&T. This involves the establishment of optical references and measurements of relevant component axes and boresights to these references as well as the construction of the PACE Spacecraft Master Reference Frame (SMRF).

b. Observatory I\&T Alignment - Online alignment measurements that support the assembly/installations on the Observatory; operations that support Observatory environmental testing and pre/postshipment alignment verification.

The PACE Spacecraft Master Reference Frame (SMRF, shown in figure 17) is the body coordinate system defined as follows:

- $\quad+\mathrm{X}$ axis is direction of the nominal velocity vector in the orbit

- $\quad+Y$ axis points toward the nominally cold space (antiSun) side of the structure

- $\quad+Z$ axis points toward the nominally Earth/nadir facing side of the structure

The origin of SMRF is at the center of the LV separation ring.

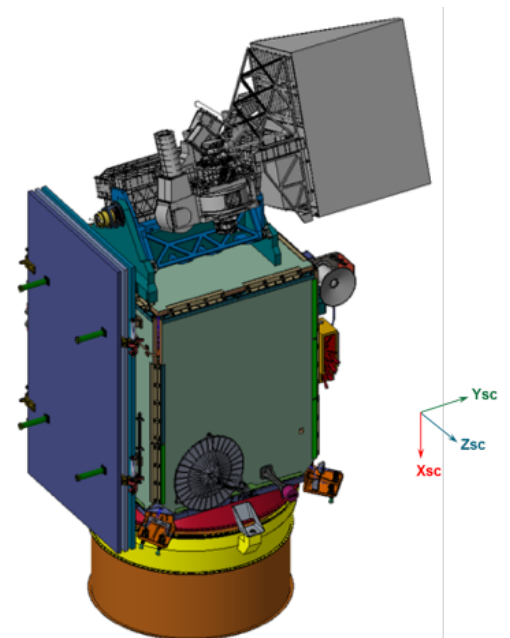

Figure 17. Spacecraft Master Reference Frame (SMRF)

Pre-Observatory I\&T Alignment consists of the establishment of the S/C Mechanical Reference Frame (SMRF) and initial knowledge and/or placement alignments of all alignment sensitive instruments and components on the spacecraft relative to the SMRF. This includes any alignment characterizations necessary to predict/measure pointing alignment of a component at the observatory level as well as characterization of the $\mathrm{S} / \mathrm{C}$ structure prior to component installations.

The physical construction of the Spacecraft (Observatory) Mechanical Reference Frame (SMRF) will be based upon design reference hole positions that can be located using Spherically Mounted Retroreflector (SMR) nests for convenient laser tracker measurement. The axial pointing of the SMRF will also be measured with respect to optical reference cubes PRC (Primary Reference Cube) and SRC (Secondary Reference Cube) using theodolite and laser tracker measurements.

The instruments, OCI, HARP2, and SPEXone, have been prealigned and each instrument will be installed to its respective instrument interface without alignment (see figure 18). A full set of baseline alignment measurements is planned with OCI in each of its tilt positions. At that time, component and instrument alignments will be verified against requirements.

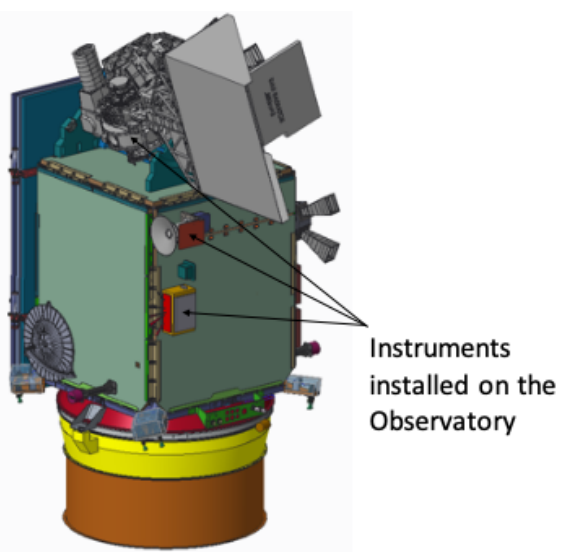

Figure 18. Observatory Level Instrument Alignment 


\section{INTEGRATION AND TEST AREAS}

The PACE FlatSat will be at GSFC in building 23. The PACE spacecraft/observatory I\&T activities will take place at GSFC in Buildings 7/10/15/29.

In building 7, the Spacecraft Checkout Area (SCA, shown in figure 19) will be used for spacecraft and observatory Integration. Contamination control will follow the PACE Observatory Contamination Control Plan [11]. Room 172 (shown in figure 20) is planned to be used as the Control room as well as I\&T teaming area.

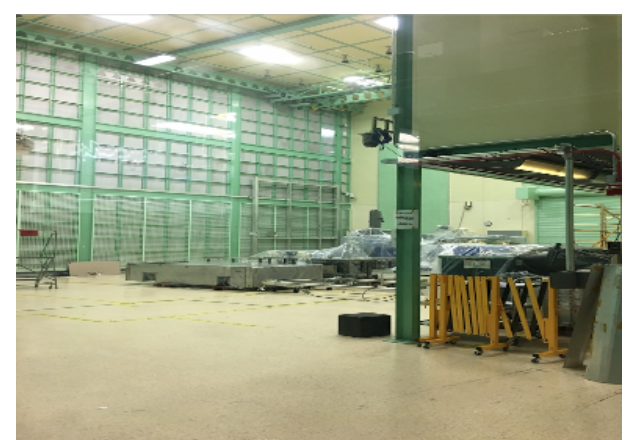

Figure 19. Spacecraft Checkout Area

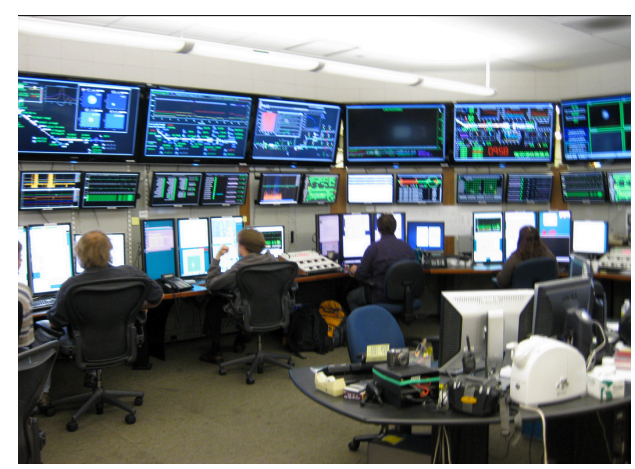

Figure 20. PACE Control Room

\section{PACE OBSERVATORY ENVIRONMENTAL TESTS AND FACILITIES}

The PACE Environmental Testing phase is kicked-off with the successful completion of the baseline CPT and the PACE Mission Pre-Environmental Review (PER). The PACE Environmental Tests planned for in order currently include:

- EMI/EMC

- Vibration/Sine Sweep

- Acoustics

- Shock

- Thermal Balance/Thermal Vacuum (TB/TV)

In general, prior to each environmental test, an Aliveness or Limited Performance Test will be performed on the observatory. It will then be configured and readied for the next scheduled environmental test. After the environmental tests, the Mass Properties/Center of Gravity (CG) test is performed.

\subsection{EMC/EMI}

The PACE instruments are capable of measuring very low level signals, down to sub- $100 \mu \mathrm{V}$, and are sensitive to common mode noise and other conducted and radiated sources from the spacecraft. Identifying and controlling the potential noise sources in the earliest phase of the PACE hardware is the highest priority of the EMI/EMC plan.

The PACE Serializer/Deserializer (SerDes) gigabit data bus and SpaceWire bus bit transition edges are equivalent to RF signals, and the high rate of these signals can be a major source of noise if it is not mitigated with the implementation of proper system grounding and impedance matched transmission lines. Other major system noise threats include the switching noise from the high speed clock, DC/DC converter and other fast switching FET devices, and the electric fields generated by the Ka-band transmitter and S-band downlink system. These sources could provide a path for RF energy to migrate to sensitive instruments electronics or detectors.

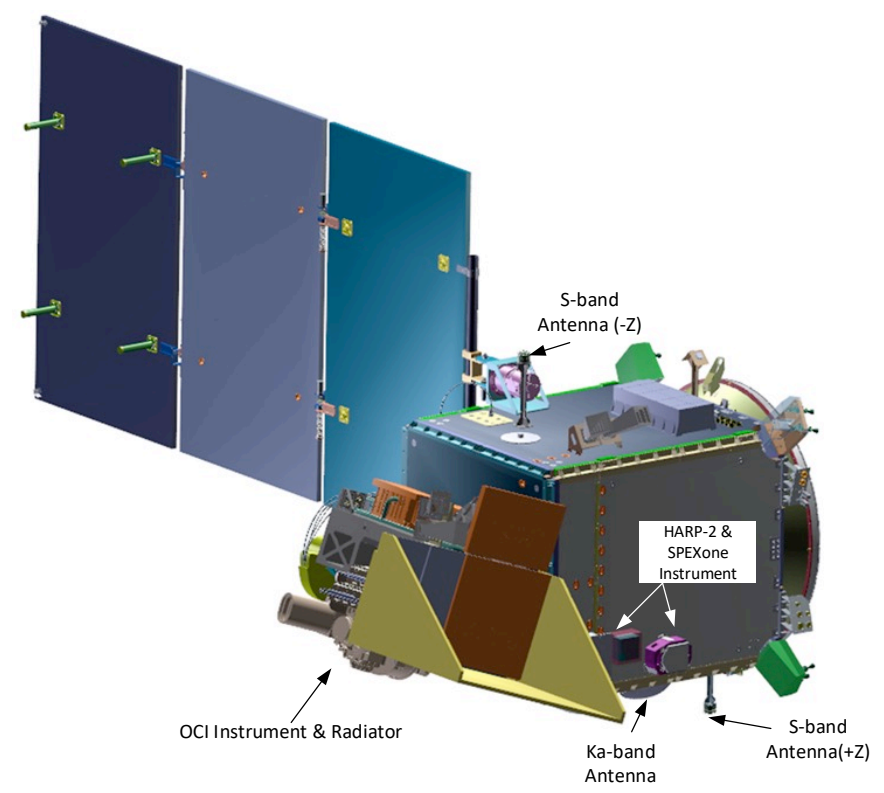

Figure 21. PACE Observatory (Deployed)

Proper grounding, filtering, emissions control, shielding and other mitigation techniques will be utilized to control the undesired EMI/EMC effects. The effectiveness of these measures will be verified by an EMI/EMC test program in the earliest phase of development using Engineering Test Unit (ETU) hardware, and formally tested during its Flight Acceptance or Qualification Test.

The Observatory level EMI/EMC test program focuses on system level compatibilities of the Observatory (shown in figure 21) under the worst case EMI environments. Mission mode radiated emissions (RE) and radiated susceptibility (RS) test will be used to verify the Observatory self-compatibility between PACE S/C bus components and instruments. The launch mode test will be used to verify the Interface Control Document (ICD) compliance to Launch Vehicle or Launch Site emissions and susceptibility requirements. 
In addition to radiated emissions (RE) and radiated susceptibility (RS) tests, a suite of special tests will be performed during Observatory level EMI/EMC testing to characterize the power bus ripple, $\mathrm{S} / \mathrm{C}$ bus common mode noise, overall grounding and electric field strength near sensitive receivers and instruments. A complete list of special tests will be generated during EMI/EMC procedure development. The PACE observatory EMI/EMC testing will be performed in the large GSFC building 7 EMI/EMC test facility with a Class $10 \mathrm{~K}$ test enclosure shown in Figure 22. OCI personnel and GSE will be located just outside the facility in the connected staging area.

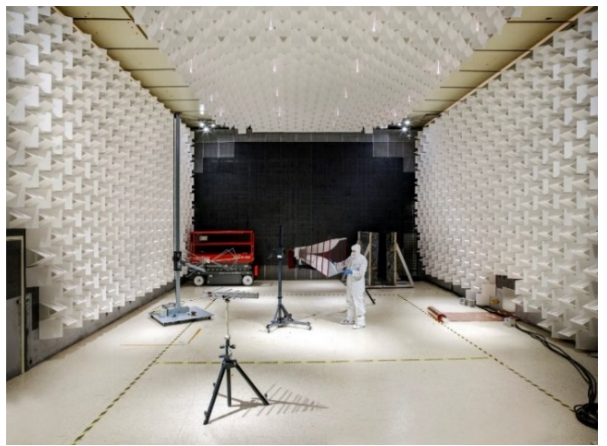

Figure 22. GSFC Large EMC/EMI Facility

\subsection{Mass Properties and CG Measurement}

The PACE observatory will use the GSFC Mass Properties Measurement Facility (MPMF) to conduct its mass properties test, that is performed before vibration test. The MPMF (shown in figure 23), consists of an air bearing measurement table and scale platform. It can be relocated to the clean room where the observatory is located. An adaptor plate will be provided which will be used to mount the observatory to the Miller Table.

The test consists of an observatory weight measurement, a two axis center of gravity measurement, and a Moment of Inertia (MOI) measurement about the vertical axis. The PACE observatory will be in near flight configuration and will be unpowered for this test. The observatory will be un-cabled from any GSE and will be electrically ground through the test fixture.

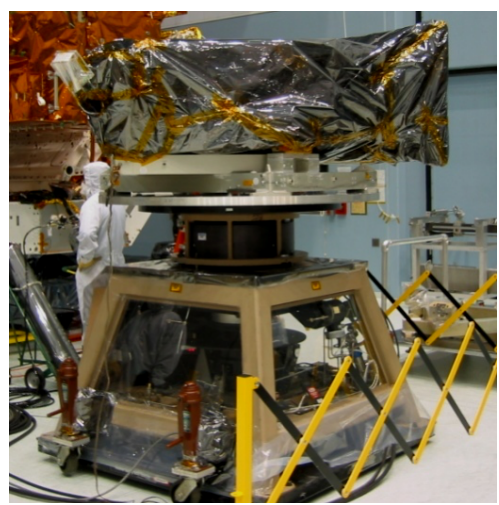

Figure 23. GSFC Mass Properties Measurement Facility

\subsection{Vibration Test}

The PACE observatory will use the GSFC building 7 Vibration Test Facilities to conduct a 3 -axis sine and random vibration test. The test campaign will utilize the T4000 shaker systems shown in Figure 24. The Vibration Test Cell is a class 100,000 clean room. Digital control systems provide sinusoidal, random, and transient waveform control to four separate electro-dynamic exciters. All exciters are rigidly mounted to very large reaction masses that are isolated from the building. Digital data acquisition systems condition and record accelerometer, force, and strain gage signals. During vibration, the observatory will be unpowered and configured in its launch configuration.

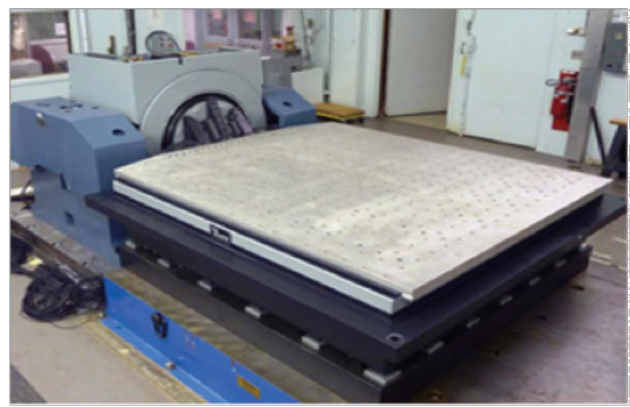

Figure 24. GSFC T4000 Shaker

\subsection{Acoustic Test}

The PACE Observatory will use the GSFC Building 10 Acoustic Facility, shown in Figure 25, to conduct an acoustic test. The Acoustic Test Cell is a class 100,000 clean room. The facility consists of a reverberant chamber, acoustic horns, noise generators, control console, and a data acquisition system. Entry into the Acoustic Test Cell facility is from the GSFC Building 10 High-Bay. This test will demonstrate that the observatory will perform without degradation when exposed to an acoustic environment representative of that encountered during launch. The specific acoustic noise levels will be based on project requirements and the selected launch vehicle. During acoustic testing, The PACE Observatory will be unpowered and configured in its launch configuration.

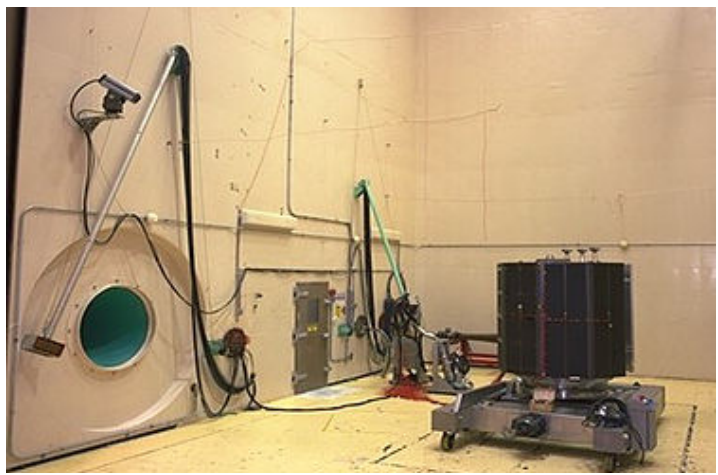

Fig 25. GSFC Acoustic facility

Acoustic energy is generated by modulating the flow of Gaseous Nitrogen (GN2) through the generator(s) attached to 
the horn(s). Fresh air through a forced ventilation system stabilizes the chamber pressure during operation of the facility and purges the chamber of GN2 for safe entry after the test.

Instrumentation data is acquired using the modular DATAMAX digital data acquisition system. A large selection of accelerometers are available for instrumenting the test item.

\subsection{Thermal Balance/Thermal Vacuum Test}

The TVAC chamber used by the PACE Observatory is the GSFC Facility 290 in building 10, also known as the Space Environment Simulator (SES, shown in figure 26 and 27). It is a very large vertical loading thermal vacuum chamber capable of achieving ultra-low pressure and a wide range of thermal conditions. In addition to the $27^{\prime} \mathrm{D} x 40$ ' $\mathrm{H}$ nitrogen shroud, two auxiliary helium shroud configurations are available $\left(25^{\prime} \mathrm{D} x\right.$ $15^{\prime} \mathrm{H}$ and $\left.25^{\prime} \times 27^{\prime} \mathrm{H}\right)$. A $1 \mathrm{~kW}$ at $20 \mathrm{~K}$ helium refrigerator is used to cool the helium shrouds and/or other auxiliary equipment. An integrated High Efficiency Particulate Air (HEPA) filtration system provides a Class 10,000 environment in the chamber and anteroom. The chamber is used for thermal vacuum and thermal balance testing, and baking out very large test articles. To load large test articles the chamber dome is rolled back to allow loading with the overhead crane. Small test articles and equipment are brought in through the personnel entrance located in the basement. Wearing of clean garments is required. Entry to instrument the payload, connect ground support equipment cabling, and install hardware is through a cleanroom air shower at the personnel door. Scaffolding may be erected to provide access to the payload. An area adjacent to the main facility control console is reserved for the experimenter's ground support equipment.

Chamber evacuation is provided by eight rotary piston mechanical pumps with Roots blowers, seven cryopumps and a turbomolecular pump. Thermal control is provided by an aluminum tube-in-sheet cylindrical shroud with both liquid nitrogen and gaseous nitrogen operational modes. The dome

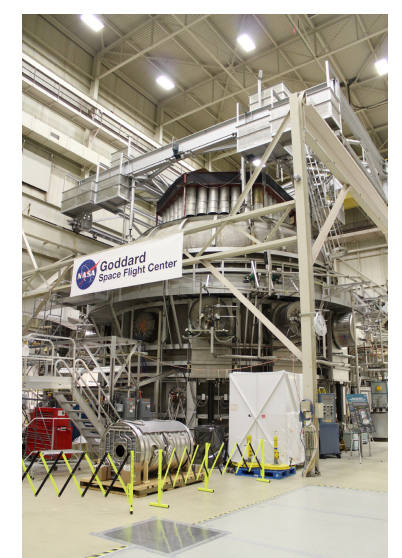

Figure 27. SES Facility and bottom shrouds are also connected to the thermal skid. Helium shrouds, resistance heater arrays and gaseous nitrogen panels are available for special thermal requirements. Thermoelectric quartz crystal microbalances (TQCMs) and a residual gas analyzer (RGA) provide both quantitative and qualitative monitoring of molecular contamination and gaseous constituents within the chamber. Closed circuit television coverage is available for monitoring the test article.

The thermal test setup consists of the chamber shroud, cold plates on auxiliary thermal conditioning units (TCUs) and/or heater plates on PID-controlled heater racks that will be used to simulate the space environment of the observatory. A Thermal Balance (TB) Test will be performed in vacuum to demonstrate the validity of the thermal design of the PACE observatory.

The PACE observatory Thermal Balance/Thermal Vacuum (TB/TVAC) profile is shown in figure 28.
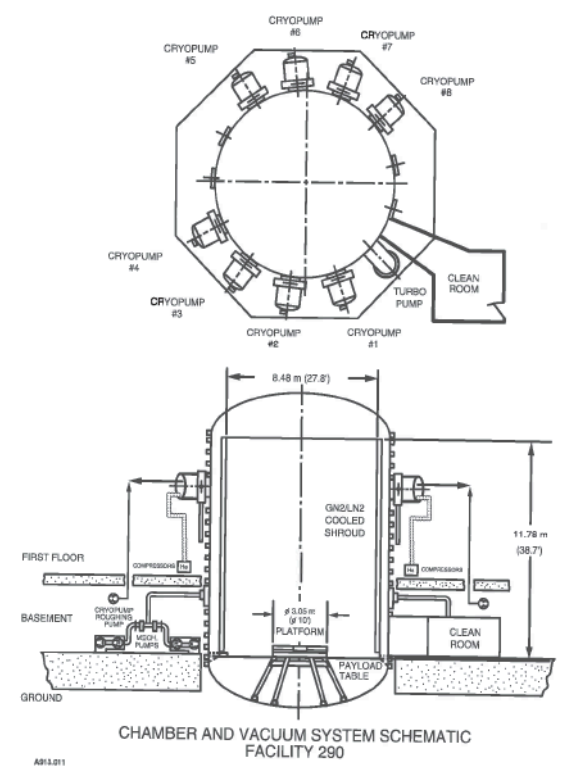

Figure 26. SES Chamber and vacuum system schematic 


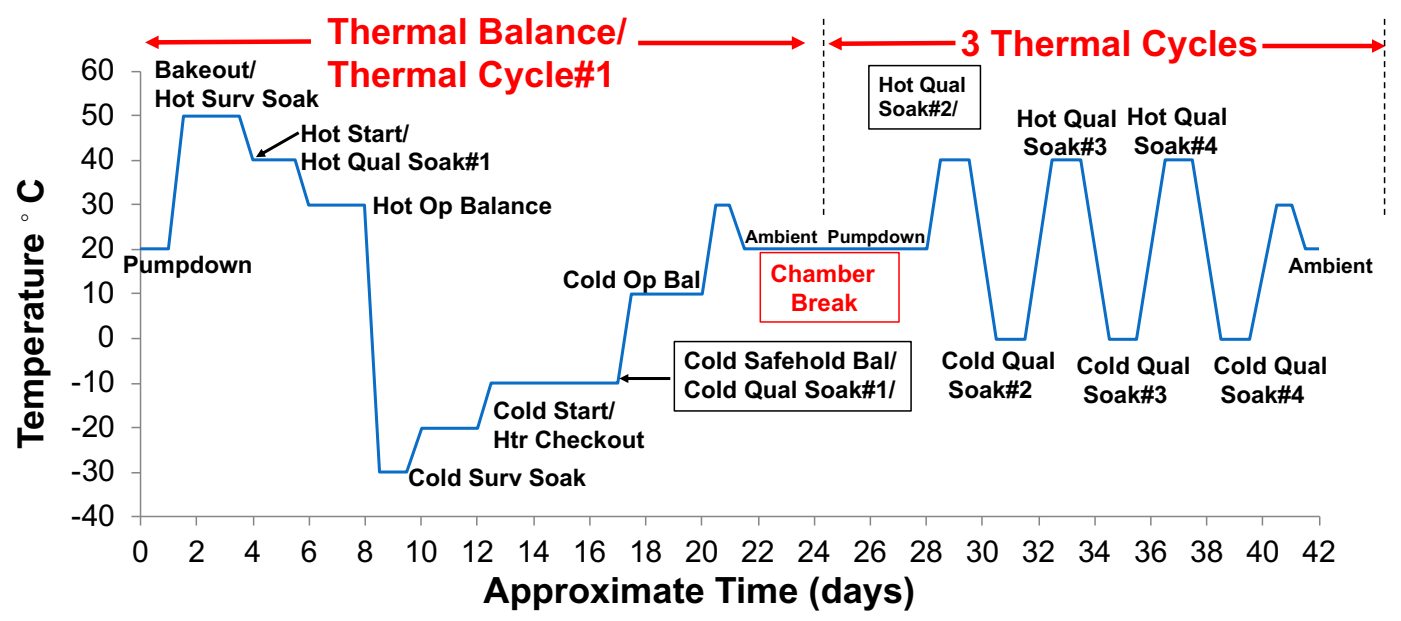

Figure 28. Observatory Thermal Balance/Thermal Vacuum (TB/TVAC) profile

\section{OBSERVATORY SHIPPING}

For the Launch Campaign, the PACE Observatory will be transported to the satellite processing facility at the NASA Western Test Range at Vandenberg Air Force Base in California. At present, the plan is to use the Modular Spacecraft Shipping Container System (MSSCS) shipping container and transport the observatory by land. The Observatory will be double bagged and the container will be actively purged with GN2 throughout the journey. A minimum of two drivers will be required to minimize significant stops during the trip. All GSE required at the launch site will be shipped separately and in advance of the Observatory to allow for set-up and readiness to receive the Observatory.

\section{LAUNCH SITE ACTIVITIES}

After arrival at the launch site, the Observatory will be unpacked and the environmental monitors checked for any anomalies that may have occurred during transport. After unpacking the launch site testing campaign begins with the post ship alignment measurements. These measurements will provide verification that the observatory alignment has not been affected by the shipment from GSFC to the launch site. The observatory will undergo post-shipment inspection, testing, cleaning, fueling and final closeouts will occur prior to mating to the launch vehicle adapter (LVA) and fairing installation. After fairing installation, an Interface Verification Test (IVT) is performed then the fairing encapsulated Observatory is transported to the facility where it is mated to the launch vehicle. Another IVT is performed and an observatory aliveness test. After rollout to the pad, an observatory pad functional test will be performed prior to launch. A top-level launch site I\&T flow is provided below (Figure 29). A lightning re-test plan is going to be developed in the event a lightning strike within a defined zone while the observatory is being processed at the launch site.

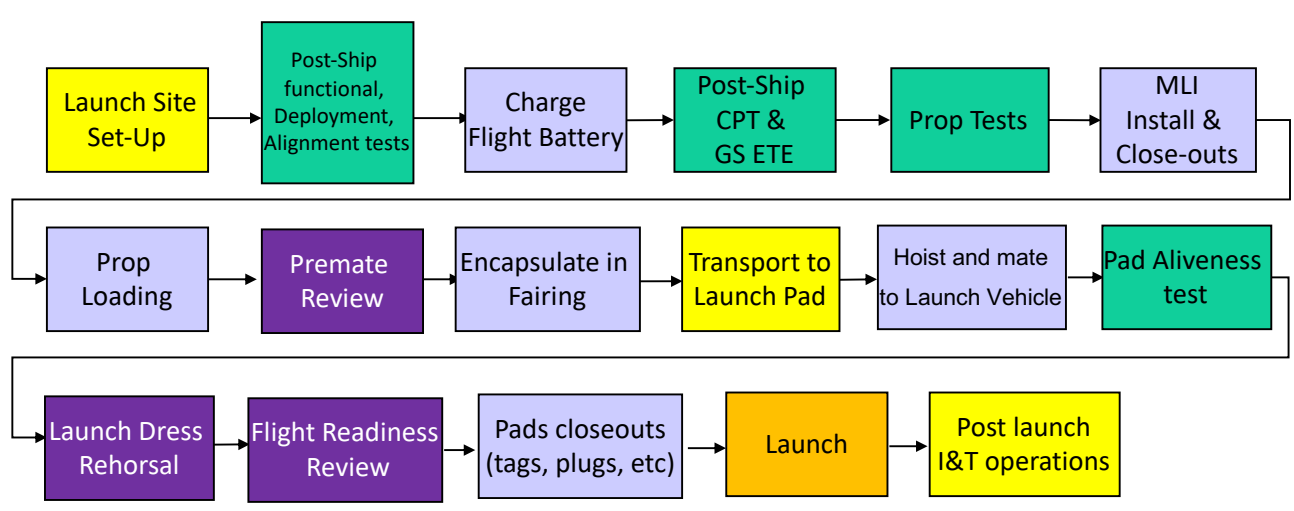

\begin{tabular}{|l|l|l|l|l|}
\hline $\begin{array}{l}\text { Set-up/Prep } \\
\text { Activity }\end{array}$ & $\begin{array}{l}\text { Integration } \\
\text { Activity }\end{array}$ & $\begin{array}{l}\text { Test } \\
\text { Activity }\end{array}$ & $\begin{array}{l}\text { Review } \\
\text { Activity }\end{array}$
\end{tabular}

Figure 29. Top-Level Launch Site Flow (see Appendix for acronyms and abbreviations) 


\section{CONCLUSIONS}

Plans, resources and facilities are in place to assure a successful PACE I\&T campaign. The I\&T plan and the verification matrix are in compliance with the latest requirements documents. Major deliverables are well understood. The baseline plan is to test as PACE will fly. As the test program matures the team may encounter tests that cannot be done in a flight like configuration of environment. The PACE Team will flag those tests that do not meet the test as you fly criteria and will report out on those at the specific reviews. At this time the team does not see any testing that will be performed outside the "as it will be flown" criteria.

Available resources are sufficient to execute the plan. It takes time and effort to integrate members of a team from different disciplines or subsystems. The PACE I\&T Manager will also integrate people through planning and coordination of I\&T activities, which will result in increased team dynamics, maximized, system testing performances, on-time delivery and reduced budget over-runs.

Key Considerations for PACE Flight Hardware Safety are: Electrostatic Discharge Protection, Contamination Control and Laser Safety. PACE personnel will receive the proper training.

All PACE Assembly, I\&T Activities will be performed at GSFC facilities. The GSFC facilities provide environmental test capability that ensures flight systems will withstand the launch and will operate properly in space environment. The GSFC Environmental Test and Integration Facilities are one of the most complete and comprehensive complexes within the United States Government.

\section{APPENDIX}

\section{ACRONYMS AND ABBREVIATIONS}

$\begin{array}{ll}\text { ACE } & \text { Attitude Control Electronics } \\ \text { ACS } & \text { Attitude Control System } \\ \text { CAB } & \text { C\&DH ACE Box } \\ \text { C\&DH } & \text { Command and Data Handling } \\ \text { CHU } & \text { Camera Heads Un } \\ \text { CNE } & \text { Center Network Environment } \\ \text { CPT } & \text { Comprehensive Performance Test } \\ \text { CSS } & \text { Course Sun Sensor } \\ \text { DC } & \text { Direct Current } \\ \text { DPU } & \text { Data Processing Unit } \\ \text { ECA } & \text { Earth Coverage Antenna } \\ \text { EGSE } & \text { Electrical Ground Support Equipment } \\ \text { EMC } & \text { ElectroMagnetic Compatibility } \\ \text { EMI } & \text { ElectroMagnetic Interference } \\ \text { ETE } & \text { End to End Test } \\ \text { ETU } & \text { Engineering Test Unit } \\ \text { FEDS } & \text { Front End Data System } \\ \text { FET } & \text { Field-Effect Transistor } \\ \text { FSW } & \text { Flight Software } \\ \text { GDS } & \text { Goddard Dynamic Simulator } \\ \text { GN\&C } & \text { Guidance Navigation and Control } \\ \text { GSFC } & \text { Goddard Space Flight Center }\end{array}$

GPS Global Positioning System

GS Ground Systems

GSE Ground Support Equipment

HEPA High Efficiency Particulate Air

IRU Inertial Reference Unit

I\&T Integration and Test

LGA Low Gain Antenna

LPT Limited performance Test

LVPC Low Voltage Power Conditioner

MLI Multilayer Insulation

MGSE Mechanical Ground Support Equipment

MTBs Magnetic Torque Bars

NENS Near Earth Network Service

PER Pre Environmental Review

OGSE Optics Ground Support Equipment

PER Pre Environmental Review

PSE Power System Electronics

PSR Pre Ship Review

RF Radio Frequency

RWA Reaction Wheel Assembly

SA Solar Array

SADA Solar Array Drive Assemblies

S/C Spacecraft

SerDes Serializer/Deserializer

SN Space Network

STS Star Tracker System

STOL Spacecraft Test and Operating Language

TAM Three-Axis Magnetometer

TSADE Tilt and Solar Array Drive Electronics

TWTA Traveling Wave Tube Amplifier

TV/TB Thermal Vacuum/Thermal Balance

UMBC University of Maryland Baltimore County

\section{REFERENCES}

[1] NASA's Plan for a Climate-Centric Architecture for Earth Observations and Applications from Space

June 2010

[2] Earth Science and Applications from Space

National Imperatives for the Next Decade and Beyond (2007)

Consensus Study Report

[3] PACE-INT-PLAN-0080 Integration and Test Plan, NASA Goddard Space Flight Center

[4] PACE-MECH-DESC-0043 PACE Mechanical Design and Control Description Document (DCD), NASA Goddard Space Flight Center

[5] S. Petro, D. Sohl, G. Hilton, M. Espiritu Ocean Color Instrument Integration and Testing October 2018 to be published in the proceedings of the IEEE Aerospace Conference 2019, Big Sky, MT, March 2-9, 2019

[6] Aerosol measurements by SPEXone on the NASA PACE mission: expected retrieval capabilities, Hasekamp et al. (2019), Journal of Quantitative Spectroscopy and Radiative Transfer 
[7] SPEXone: A compact multi-angle spectro-polarimeter, van Amerongen et al. (2018), International Conference on Space Optics

[8] PACE-INT-PLAN-0083, Revision A PACE Integration and Test Subsystem Implementation Plan (SIP), NASA Goddard Space Flight Center

[9] NASA GPR 8730.1I, Calibration and Metrology

[10] PACE-SYS-REQ-0019 PACE Mission Requirements Document, NASA Goddard Space Flight Center

[11] PACE-SYS-PLAN-0019 PACE Contamination Control Plan (CCP), NASA Goddard Space Flight Center

[12] PACE-MECH-PLAN-0173, PACE Observatory Alignment Plan, NASA Goddard Space Flight Center

\section{BIOGRAPHY}

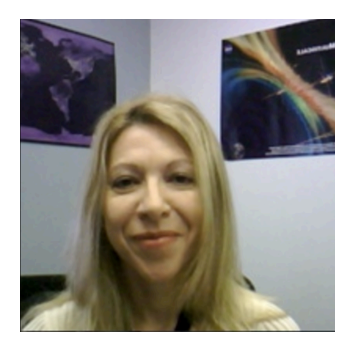

Susanna Petro has more than 30 years of experience in spacecraft and instrument systems design, test, and launch. She currently works as Staff Engineer in the Flight Systems Integration and Test Branch at the Goddard Spaceflight Center. She previously worked at the GOES-R Project supporting the Space Environment In-Situ Suite instruments for technical design, calibration and testing. Before that, she worked at the Johnson Space Center with the Electromagnetic Interference/Compatibility Test \& Analysis Group. She obtained a doctor's degree in Experimental Nuclear Physics from the University of Rome, Italy La Sapienza.

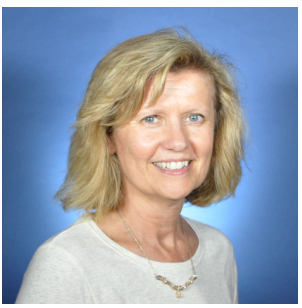

Karen Pham has more than 30 years of experience in aerospace. She earned her B.S. degree in Electrical Engineering from the University of Maryland-College Park and her M.S. degree from the George Washington University, Electrical Engineering (Communications). She works at Goddard Space Flight Center since 1987. She has served as the Deputy I\&T Manager for Astro-H Soft X-ray Spectrometer (SXS) and for the Magnetospheric Multiscale (MMS). She was on the Mishap Investigation Board (MIB) for the GOES-R Thermal Vacuum Heater Cable Anomaly. She worked as the $I \& T$ Manager for the Neutron star Interior Composition ExploreR (NICER) and the Global Ecosystem Dynamics Investigation (GEDI). She is actually the Plankton, Aerosol, Cloud, Ecosystem (PACE) Integration and Test Manager.

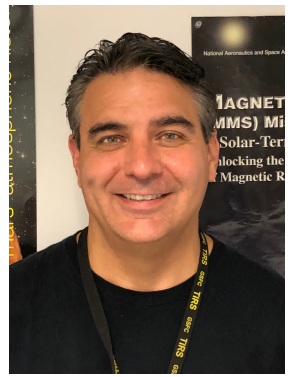

George Hilton is a Senior Engineer and Researcher with twenty-five years of experience at NASA Goddard. He is involved in the development of technological advances and meeting engineering challenges in the development, fabrication, testing, and assembly of ground-based and spacebased science instruments. He received a B.A. in Mechanical Engineering and a MS in Materials Science Engineering from the University of Maryland at College Park. 